\title{
Syngas Molecules as Probes for Defects In 2D Hexagonal Boron Nitride: their Adsorption and Vibrations
}

Received 00th January 20xx, Accepted 00th January 20xx DOI: $10.1039 / \times 0 \times x 00000 x$

\begin{abstract}
Tao Jiang, ${ }^{a}$ Duy Le, ${ }^{a, b}$ Takat B. Rawal, ${ }^{a}+$ and Talat S. Rahman ${ }^{a, b *}$
Single-layer, defect-laden hexagonal boron nitride $(d h-\mathrm{BN})$ is attracting a great deal of attention for its diverse applications: catalysis on the one hand, and single photon emission on the other. As possible probes for identifying some common defects in single-layer $h$-BN, we present results of $a b$ initio calculations for the adsorption and vibrational characteristics of syngas molecules $\left(\mathrm{H}_{2}, \mathrm{CO}, \mathrm{CO}_{2}\right)$ on dh-BN containing one of four types of defects: nitrogen vacancy $\left(\mathrm{V}_{\mathrm{N}}\right)$, boron vacancy $\left(\mathrm{V}_{\mathrm{B}}\right)$, StoneWales defect $(\mathrm{SW})$, and nitrogen substituted by boron $\left(\mathrm{B}_{\mathrm{N}}\right)$. Through a comparative examination of adsorption features, charge transfer, electronic structure, and vibrational spectrum, we obtain a deep understanding of the interaction of these molecules with $d h-\mathrm{BN}$ and the role of the defect states. We find that while $\mathrm{CO}$ and $\mathrm{CO}_{2}$ chemisorb, molecular $\mathrm{H}_{2}$ physisorbs, but dissociative adsorption of $\mathrm{H}_{2}$ is feasible on $d h-\mathrm{BN}$. $\mathrm{V}_{\mathrm{N}}$ and $\mathrm{V}_{\mathrm{B}}$ show strong affinity for $\mathrm{CO}$ and $\mathrm{CO}_{2}$ since the defect states induced by them lie close to the Fermi level. SW does not favor adsorption of these small molecules, as the process for each is endothermic. At $\mathrm{B}_{\mathrm{N}} \mathrm{CO}$ adsorbs strongly but $\mathrm{CO}_{2}$ only weakly. Vibrational frequencies of notable modes localized at the adsorbed molecules are analyzed and suggested as measures for identification of the defect type. Systematically investigating the adsorption of small molecules on these defects, we predict that $d h-\mathrm{BN}$ with $\mathrm{V}_{\mathrm{N}}$ is a good catalyst candidate for $\mathrm{CO}_{2}$ hydrogenation.
\end{abstract}

\section{Introduction}

Similar to other two dimensional (2D) materials, single-layer hexagonal boron nitride ( $h$-BN) has received considerable attention in the past few years owing to its novel properties that make it amenable for various applications. ${ }^{1}$ Structurally analogous to graphene, single-layer $h$-BN has $\mathrm{B}$ and $\mathrm{N}$ atoms arranged in a hexagonal lattice and bound together by strong covalent bonds. It is a wide bandgap material with the high chemical stability ${ }^{2}$ and ideally suited as a reliable support for other 2D materials. ${ }^{3}$ Its unique properties have also suggested its potential usage in optoelectronics ${ }^{4}$ and photo-catalysis. ${ }^{5}$ Even more remarkable have been the recent findings of its suitability as a catalyst ${ }^{1,6,7}$ and as single photon emitter, ${ }^{8-10}$ raising questions about the role of defects. This is to be expected as pristine $h$-BN is chemically inert because of the lack of dangling bonds. ${ }^{11}$ It therefore calls for prudent ways to activate the basal plane of $h$-BN. Taking cues from prior studies on $\mathrm{MoS}_{2},{ }^{12-17}$ proposals have been made to activate the basal plane on $h$-BN by the creation of defects, ${ }^{18,}{ }^{19}$ deposition of metal atoms or molecules, ${ }^{20-23}$ creation of grain-boundaries, ${ }^{24}$ and application of strain to the defective surface. ${ }^{25}$ Quite akin to defect-laden single-layer $\mathrm{MoS}_{2}$ (with sulfur vacancies), which

\footnotetext{
a. Department of Physics, University of Central Florida, Orlando, FL, 32816 USA b. Renewable Energy and Chemical Transformations Cluster, University of Central Florida, Orlando, FL, 32816 USA

*Email: talat.rahman@ucf.edu

†Present address: Department of Physics, University of Houston, Houston, TX 77204 USA
}

calculations predict to be a possible catalyst for hydrogenation of syngas to alcohol, ${ }^{12}$ the basal plane of the single-layer $h$-BN can be chemically activated for similar reaction, in the presence of point or line defects on the surface. Indeed, in the above mentioned experimental and theoretical study ${ }^{6}$ showing propane hydrogenation, the activity was traced to the presence of defects. While nitrogen vacancy has been proposed as the most active defect, interestingly for both catalytic ${ }^{6}$ and singlephoton emissive ${ }^{8}$ properties, the role of other types of defects cannot be ruled out. Defects are, however, not easy to characterize experimentally, notwithstanding the nanometer resolution scanning tunneling microscopy (STM) studies by Feng et al. ${ }^{9}$ Small molecules such as $\mathrm{H}_{2}, \mathrm{CO}, \mathrm{CO}_{2}$, the syngas trio, could serve as probe of defects through their adsorption and vibrational characteristics on $d h$-BN.

Beyond serving as probes of defects, an in-depth understanding of the relative propensity of common defect types in facilitating adsorption of syngas molecules on $d h-\mathrm{BN}$ is the first step in rational designing of $d h-\mathrm{BN}$ for specific hydrogenation reactions. The topic is of broad interest since $h$-BN is readily available and thermally stable. With appropriate defects it could serve as a metal-free catalyst for hydrogenation of $\mathrm{CO} / \mathrm{CO}_{2}$ even at ambient or higher temperatures. To probe the catalytic properties of $h$-BN toward such hydrogenation, it is thus essential that we gain fundamental insights into the interactions between $h$-BN and syngas, as presented in this work. It should be noted that adsorption of $\mathrm{H}_{2}, \mathrm{CO}$, and $\mathrm{CO}_{2}$ (syngas) on solid catalyst materials are the fundamental processes and the starting points of the reaction pathway of their conversion into useful (value-added) chemical products, i.e., simple to higher 
alcohols, formaldehyde, formic acid, and higher hydrocarbons. ${ }^{26-28}$ The thermodynamic favorability and kinetic stability of the adsorption of syngas molecules on the catalyst surface are critical for efficiently and selectively promoting hydrogenations of $\mathrm{CO}$ and $\mathrm{CO}_{2}{ }^{29}$ In fact, it requires an appropriate catalyst material which should be thermally stable, chemically active and selective for the desired reaction products. Historically, metal-based catalysts have been widely investigated and utilized for hydrogenation reaction, as they typically demonstrate good catalytic activity and product selectivity. ${ }^{26-28}$ The optimal catalyst material is, however, often an expensive, non-abundant metal and/or can be easily oxidized and deactivated. Copper-based catalysts ${ }^{28}$ are not expensive but they have poor thermal stability, and hence not suitable for high-temperature reactions without a thermal stabilizer. Cerium-based catalysts ${ }^{30}$ have also shown good activity and selectivity for $\mathrm{CO}_{2}$ hydrogenation process, but are easily deactivated by a small coverage of deposited carbon. There is thus a need to develop cost-effective catalyst material which has superior properties for syngas conversion than presently available.

With the above in mind, we present here results of $a b$ initio calculations, based on density functional theory (DFT) of the adsorption of syngas on the $d h$-BN layer with one of four possible types of defects - nitrogen vacancy $\left(V_{N}\right)$, boron vacancy $\left(V_{B}\right)$, stone-wales $(S W)$, and nitrogen substituted by boron $\left(B_{N}\right)$ which have been shown to have affinity towards the selected adsorbates. ${ }^{6}$ To probe the reactivity of single-layer $h$-BN with these defects, we compare the adsorption and vibrational characteristics of syngas molecules on them. We examine the favorable sites and orientation of these molecules on $d h-\mathrm{BN}$ and analyze the unique local atomic environment and electronic structure of $d h$-BN as modified by the adsorbed molecules $\left(\mathrm{H}_{2}\right.$, $\mathrm{CO}$ and $\mathrm{CO}_{2}$ ). Quite importantly, we calculate and analyze vibrational frequencies of modes localized at the adsorbed molecules and nearby defect sites to identify notable vibrational frequencies as possible signatures of the adsorption, and thereby the defect type. Based on the DFT-calculated energetics for syngas-adsorption, we show that the $h$-BN with nitrogen vacancy may serve as a potential metal-free catalyst material for hydrogenation of $\mathrm{CO}_{2}$.

In the next section, we introduce details of our computational methodology. We next presents results and discussion, starting with the geometrical and electronic structure of the four types of point defects in $h$-BN considered in this work, followed by the adsorption and vibrational analysis of $\mathrm{H}_{2}, \mathrm{CO}$, and $\mathrm{CO}_{2}$ on the defects and the discussion of implication of our results towards the catalytic activity of $h$-BN. Finally, we provide main conclusions of this work.

\section{Computational details}

All calculations are performed by using spin-polarized DFT, implemented in the Quantum Espresso Code, ${ }^{31}$ employing plane-wave basis set and the projected-augmented-wave (PAW) method $^{32,}{ }^{33}$ for interaction between electrons and nuclei. We use the vdW-DF2 functional ${ }^{34}$ for exchange- correlation of electrons as it is found to produce excellent lattice constant of $h$-BN. We use the plane wave basis set with kinetic energy cutoff of $45 \mathrm{Ry}$ and charge density with 180 Ry. We construct a $(6 \times 6)$ supercell of single layer hexagonal boron nitride ( $h$-BN) with periodic boundary conditions along in-plane directions and a vacuum of $20 \AA$ to avoid the spurious interaction between periodical images. To model a defect-laden $h$-BN system (so-called $d h$-BN), we remove either a boron/nitrogen atom or substitute a nitrogen atom by a boron atom or rotate a B-N bond by 90 degree. The relaxed structures of our model systems of $h$-BN with various defects, namely, nitrogen vacancy $\left(V_{N}\right)$, boron vacancy $\left(V_{B}\right)$, Stone Wales defect (SW) and nitrogen substituted by boron $\left(B_{N}\right)$ are shown in Figure 1. To investigate the adsorption characteristics of $\mathrm{H}_{2}, \mathrm{CO}$ and $\mathrm{CO}_{2}$ we place single molecule at the defect site and at the neighboring atoms near defect sites (We will present only the lowest-energy adsorption structures). All systems are relaxed until their energy converges to $10^{-6} \mathrm{eV}$ and the residual force on each atom reaches below $0.005 \mathrm{eV} / \AA$. For calculations of geometry relaxation, we sample the Brillouin zone with one point at the zone center and for electronic density of states, we use a $12 \times 12 \times 1 \mathrm{k}$-point mesh.

The adsorption energy is defined as $\mathrm{E}_{\mathrm{ads}}=\mathrm{E}_{\mathrm{Molecule} / d h-\mathrm{BN}}-$ $\left(\mathrm{E}_{\text {Molecule }}+\mathrm{E}_{d h-\mathrm{BN}}\right)$, where, $\mathrm{E}_{\text {Molecule } / d h-\mathrm{BN}}, \quad \mathrm{E}_{\text {Molecule, }}$ $\mathrm{E}_{d h-\mathrm{BN}}$ are the total energy of the molecule on $d h-\mathrm{BN}$, isolated molecule, and $d h$-BN system, respectively. We calculate charge density difference upon adsorption of molecules on $d h$-BN using: $\quad \Delta \rho=\rho_{\text {Molecule } / d h-\mathrm{BN}}-\left(\rho_{\text {Molecule }}+\rho_{d h-\mathrm{BN}}\right)$, where $\rho_{\text {molecule } / d h-\mathrm{BN}}, \rho_{d h-\mathrm{BN}}$, and $\rho_{\text {Molecule }}$ are charge density of the molecule on $d h-\mathrm{BN}, d h-\mathrm{BN}$ itself, and the isolated molecule, respectively. We calculate charge on each atom using Bader charge analysis ${ }^{35,} 36$ which allows estimation of the charge transfer between the molecule and $d h-B N$. Vibration frequencies were calculated using the finite-difference method as implemented in the Phonopy package, ${ }^{37}$ in which we use a displacement of $0.01 \AA$ to maintain the validity of the harmonic approximation and avoid numerical errors that would otherwise introduce chaotic behavior in the result. Zero point energy (ZPE) correction for the total energy of each system is calculated as $\sum_{i=1}^{N} \hbar v_{\mathrm{i}} / 2$, where $\hbar$ is the Planck constant, $v_{\mathrm{i}}$ is the frequency of vibrational mode $i(i=1 . . N$, where $N$ is the total number of vibrational modes of the system).

\section{Results and Discussions}

\section{Geometrical and Electronic Structure of dh-BN}

We present in Figure 1 the geometry of the considered four types of defect in single-layer $h-B N, V_{N}, V_{B}, S W$, and $B_{N}$. To explore their electronic structure, we show the spin dependent density of states of each defect in Figure 2. 

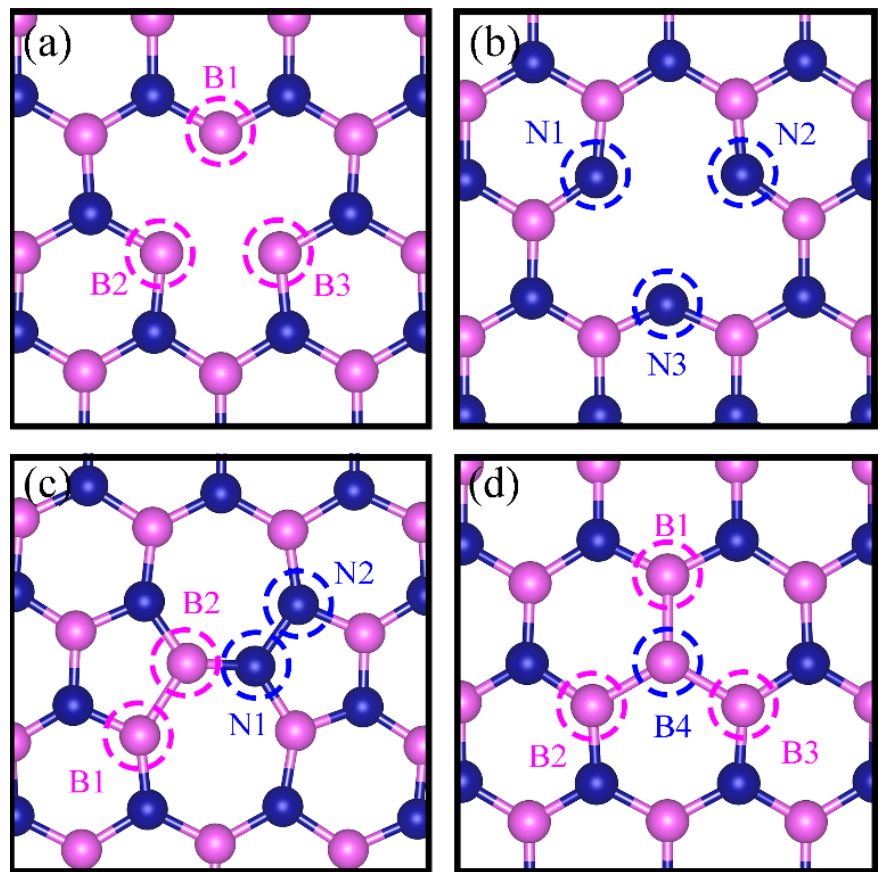

Figure 1 Schematic representation of $h$-BN model systems with defects: (a) $V_{N}$, (b) $V_{B}$, (c) $\mathrm{SW}$, and (d) $\mathrm{B}_{\mathrm{N}}$. Blue and magenta balls represent $\mathrm{N}$ and $\mathrm{B}$ atoms, respectively.
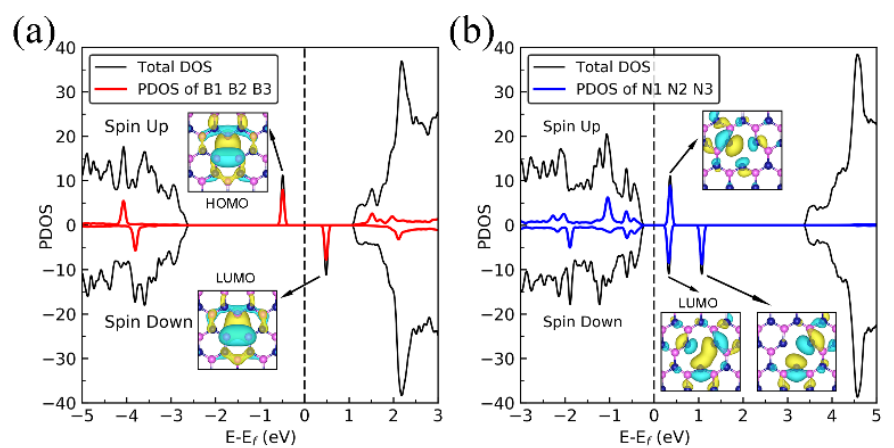

(c)

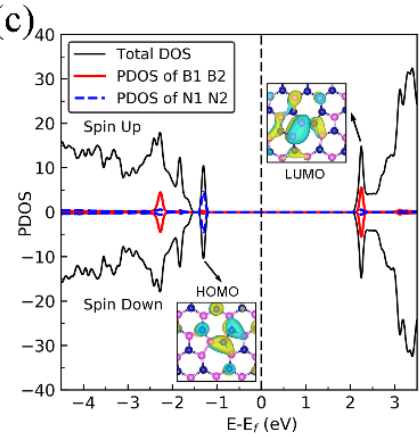

(d)

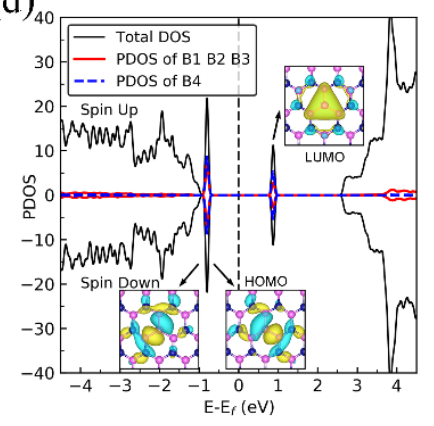

Figure 2 Spin-polarized projected density of states (PDOS) of $d h$-BN with defects: (a) $V_{N}$ (b) $V_{B}$, (c) SW, and (d) $B_{N}$. The inset displays the wave function of the defect states with isosurface value of $0.001|\mathrm{e}| / \AA$.

\section{Nitrogen vacancy $\left(\mathrm{V}_{\mathrm{N}}\right)$}

The presence of a nitrogen vacancy on the $h$-BN surface leads to a local geometrical change (Figure $1 \mathrm{a}$ ) as reflected by changes in the bond lengths and bond angles. The distance between $B$ and $\mathrm{N}$ atoms $\left(\mathrm{d}_{(\mathrm{B} 2-\mathrm{N})}\right)$ is $1.492 \AA$, to be compared to $1.454 \AA$ of the pristine $h-\mathrm{BN}$, whereas the angle between $\mathrm{N}, \mathrm{B}$ and $\mathrm{N}$ atoms $\left(\theta_{(\mathrm{N}-\mathrm{B} 2-\mathrm{N})}\right)$ is $113.6^{\circ}$ as opposed to $120^{\circ}$ in pristine $h$-BN. Also, the separation between $\mathrm{N}$ atoms, $\mathrm{d}_{(\mathrm{N}-\mathrm{N})}$, is changed from 2.485 to $2.471 \AA ̊$ ( $0.5 \%$ change $)$.

From spin-polarized calculations of electronic density of states in Figure $2 \mathrm{a}$, we find that $d h-\mathrm{BN}\left(\mathrm{V}_{\mathrm{N}}\right)$ is a spin-polarized system the effect arising from the unpaired electrons produced by the $\mathrm{N}$ vacancy. Of critical importance are the two mid-gap states, one is spin-up - the highest occupied molecular orbital (HOMO) - and the other is spin-down - the lowest unoccupied molecular orbital (LUMO). These states are separated by $0.98 \mathrm{eV}$. The wave functions of HOMO and LUMO (Inserts in Figure 2a) adapt the same symmetry and are $\pi$-type orbitals, which are localized at the vacancy, i.e., at the B1, B2, B3 atoms (shown in Figure 1a) and surrounding the $N$ and $B$ atoms. The mid-gap states are mostly contributed from B1, B2, and $\mathrm{B} 3$ atoms, as shown in Figure 2a.

\section{Boron vacancy $\left(V_{B}\right)$}

The existence of a boron vacancy on single-layer $h$-BN leads to the following geometrical change at the defect (Figure 1b): as compared to those in pristine $h-\mathrm{BN}$, the distance between $\mathrm{N}$ and $\mathrm{B}$ atoms $\left(\mathrm{d}_{(\mathrm{B}-\mathrm{N} 1)}\right)$ shortens from $1.455 \AA$ to $1.419 \AA$ ( $2.5 \%$ change); the angle between $B, N$ and $B$ atoms $\left(\theta_{(B-N 1-B)}\right)$ enlarges from $120^{\circ}$ to $129.3^{\circ}$ ( $7.8 \%$ change); and the distance between $\mathrm{N}$ atoms, i.e. $\mathrm{d}_{(\mathrm{N}-\mathrm{N})}$, elongates from $2.520 \AA$ to $2.565 \AA(1.8 \%$ change). The $d h$-BN with $V_{B}$ also possesses spin-polarized electronic DOS, as indicated by the calculated spin-up and down DOS shown in Figure $2 \mathrm{~b}$. The presence of $B$ vacancy leads to unsaturation of the bonds for the nearest-neighboring N (N1, $\mathrm{N} 2$, and N3) atoms. As shown in the inset in Figure 2b, the LUMO orbital in the spin-down channel is a $\sigma$-type orbital, located near the valence band edge of $h$-BN. As indicated in PDOS of $\mathrm{N} 1 / \mathrm{N} 2 / \mathrm{N} 3$ atoms (blue curve Figure $2 \mathrm{~b}$ ), the LUMO and two other mid-gap states (above LUMO, one is spin up and the other is spin down)are mainly composed of the states of N1/N2/N3 atoms, which is similar to the results of Huang et.al. ${ }^{18}$

\section{Stone-Wales (SW) Defect}

The Stone-Wales (SW) defect is created by rotation of a B-N bond by $90^{\circ}$ around its midpoint, as shown in Figure $1 \mathrm{c}$. The bond lengths of B1-B2, B2-N1, N1-N2 are found to be $1.686 \AA$, $1.375 \AA$ and $1.478 \AA$, respectively. The PDOS of $d h$-BN (SW), shown in Figure 2c, indicates that occupied and unoccupied defect states are not spin-polarized. The unoccupied defect states (LUMO) above the Fermi level are mainly contributed by the B1 and B2 atoms with a small contribution from the atoms surround $B 1$ and $B 2$ atoms while the occupied defect states (HOMO) below the Fermi level have main contributions from N1 and $\mathrm{N} 2$ atoms. The LUMO states are $\sigma$-type dominated by $p_{x}$ and $p_{y}$ orbitals from the B-B bond, while the HOMO states are $\pi$ type, in agreement with Ref. $\left[{ }^{38}\right]$.

\section{B substitution for $\mathbf{N}\left(B_{N}\right)$}

$\mathrm{B}_{\mathrm{N}}$ defects are formed by the substitution of a $\mathrm{B}$ atom for a $\mathrm{N}$ atom at the lattice of pristine $h$-BN as shown in Figure $1 \mathrm{~d}$. The bond lengths of $B-B$ and N-B are found to be $1.627 \AA$, $1.452 \AA$, respectively. The PDOS plot, Figure $2 \mathrm{~d}$, obtained for $d h$-BN with $B_{N}$ clearly displays its large bandgap with non-spin-polarized 
defect-related gap states. Since boron has two fewer valence electrons than nitrogen, dangling bonds are formed. In the defect levels below and above the Fermi level, atom B4 makes larger contribution than the sum of the contributions from atoms B1, B2, and B3. Note that $\mathrm{H}$. Choi et $\mathrm{al}^{39}$ have already analyzed electronic properties of boron nitride nanotube with $B_{N}$. In our case, the B4 atoms and its surrounding boron atoms of the single layer $d h-\mathrm{BN}\left(\mathrm{B}_{\mathrm{N}}\right)$ resemble the geometry in the boron nitride nanotube with $B_{N}$, indicating similar electronic properties of $B_{N}$. We also find that the $B_{N}$ defect introduces unoccupied defect states (LUMO) in the middle of the energy gap and occupied defect states (HOMO) near the valence band edge. These are $\sigma$-type orbitals with similar geometric structure in comparison with those in the nanotube with $\mathrm{B}_{\mathrm{N}}{ }^{39}$

\section{Adsorption of small molecules on $d h-B N$}

\section{Hydrogen molecule on $d h$-BN}

Figure 3 shows the optimized geometries of $\mathrm{H}_{2}$ on $d h-\mathrm{BN}$ with $V_{N}, V_{B}, S W$ and $B_{N}$. We find that $H_{2}$ molecule only physisorbs on single layer $d h$-BN with the adsorption energy of $-0.07 \mathrm{eV},+0.08$ $\mathrm{eV},-0.08 \mathrm{eV}$ and $-0.08 \mathrm{eV}$, at $\mathrm{V}_{\mathrm{N}}, \mathrm{V}_{\mathrm{B}}, \mathrm{SW}$ and $\mathrm{B}_{\mathrm{N}}$, respectively. The bond length of $\mathrm{H}-\mathrm{H}$ of $\mathrm{H}_{2}$ on all four defects is $0.737 \AA$, which is almost identical to $\mathrm{H}-\mathrm{H}$ bond length of $0.735 \AA$ in the gas phase. The distance $d_{(H-B)}$ for $H_{2}$ is $3.359 \AA$, $3.267 \AA$, and 3.357 $\AA$, on $V_{N}, S W$ and $B_{N}$, respectively. The distance $d_{(H-N)}$ for $H_{2}$ on $\mathrm{V}_{\mathrm{B}}$ is $3.285 \AA$. Electron transfer from the $d h$-BN to $\mathrm{H}_{2}$ molecules is found to be negligible $(0.005,0.004,0.002$, and $0.004 \mathrm{e}$, on $V_{N}, V_{B}, S W$ and $B_{N}$, respectively). Such small electron transfer reflects the fact that the $\mathrm{H}_{2}$ molecule is physisorbed on $d h-\mathrm{BN}$, consistent with almost-unchanged $\mathrm{H}-\mathrm{H}$ bond lengths.

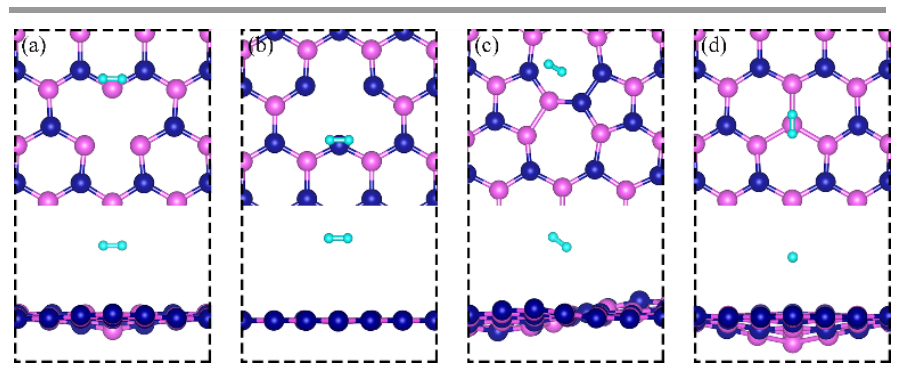

Figure 3 Optimized structures of $H_{2}$ adsorbed at favored sites of $h-B N$ with a) $V_{N}$, b) $V_{B}$, c) SW, and d) $B_{N}$. The magenta, blue, white balls represent the $B, N$ and $\mathrm{H}$ atoms, respectively. The top and bottom panel shows the top and side views, respectively.

\section{Adsorption of two Atomic Hydrogens on dh-BN}

Since $\mathrm{H}_{2}$ does not chemisorb in molecular form on $d h$-BN with $V_{N}, V_{B}, S W$ and $B_{N}$, we turn to investigate the adsorption of the molecule in the form of two atomic hydrogens on $d h-B N$. Binding geometries of two adsorbed atomic hydrogens $(2 \mathrm{H})$ on the four considered types of $d h-\mathrm{BN}$ substrates are shown in Figure 4. The geometries of the most stable adsorption sites are similar to those in previous work by Nash. et al. ${ }^{6}$ The calculated energetic and geometric parameters, including the adsorption energy, $\mathrm{H}-\mathrm{H}$ distance, and the distance of formed $\mathrm{B}(\mathrm{N})-\mathrm{H}$ bond, are summarized in Table 1.

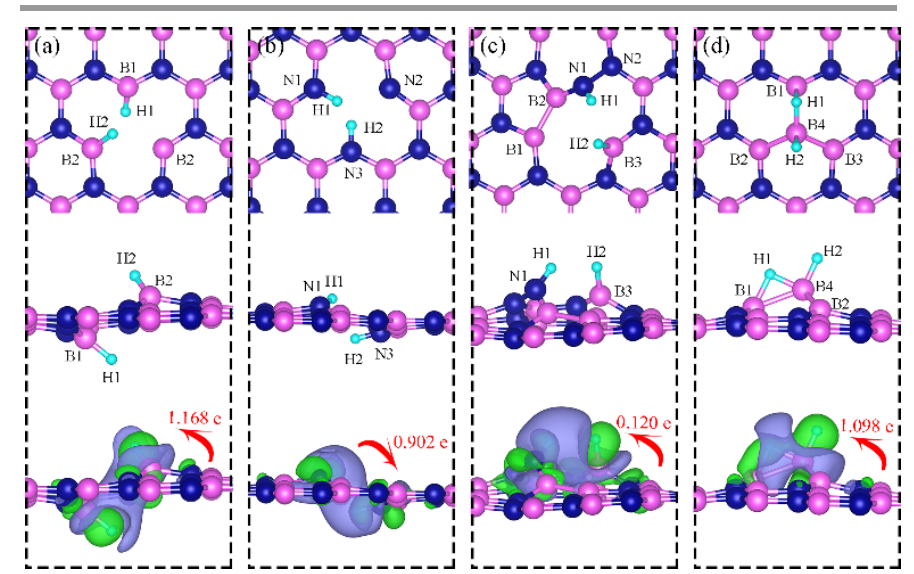

Figure 4 Optimized structures of two hydrogen atoms adsorbed at energetically favorable sites on single layer $d h-B N$ with a) $V_{N}$, b) $\left.V_{B}, c\right) S W$, and d) $B_{N}$. The magenta, blue, cyan balls represent the $B, N$ and $H$ atoms, respectively. The top and middle panel shows the top and side views, respectively. Bottom panel: the corresponding side views of the geometric structures with the charge density difference plot. The green and violet isosurfaces with isovalue of $\pm 0.003 \mathrm{e} / \AA^{3}$, represent the accumulation and depletion of charge, respectively. The red arrow shows the direction of electron transfer evaluated with Bader charge analysis.

Table 1 The adsorption energy without $\left(E_{\text {ads }}\right)$ and with $\left(E^{\prime}{ }_{\text {ads }}\right)$ ZPE correction, geometrical parameters, and notable frequencies for adsorption of 2 atomic Hydrogen on $d h$-BN.

\begin{tabular}{|c|c|c|c|c|c|}
\hline Defects & Sites & $\begin{array}{l}\text { Eads } \\
(\mathrm{eV})\end{array}$ & $\mathrm{E}^{\prime}{ }_{\mathrm{ads}}(\mathrm{eV})$ & $\begin{array}{l}\text { Distance } \\
\text { between } \\
\text { atoms }(\AA)\end{array}$ & $\begin{array}{c}\text { Notable } \\
\text { frequencies } \\
\left(\mathrm{cm}^{-1}\right)\end{array}$ \\
\hline $\mathrm{V}_{\mathrm{N}}$ & $\begin{array}{l}\text { B1, } \\
\text { B2 }\end{array}$ & -1.61 & -1.32 & $\begin{array}{c}\mathrm{d}_{(\mathrm{H}-\mathrm{H})}=3.087, \\
\mathrm{~d}_{(\mathrm{H} 1-\mathrm{B} 1)}=1.189 \\
\mathrm{~d}_{(\mathrm{H} 2-\mathrm{B} 2)}=1.190\end{array}$ & $\begin{array}{l}2550.4 \mathrm{~cm}^{-1} \\
2554.5 \mathrm{~cm}^{-1}\end{array}$ \\
\hline $\mathrm{V}_{\mathrm{B}}$ & $\begin{array}{l}\text { N1, } \\
\text { N2 }\end{array}$ & -4.61 & -4.13 & $\begin{array}{l}\mathrm{d}_{(\mathrm{H}-\mathrm{H})}=1.869, \\
\mathrm{~d}_{(\mathrm{H} 1-\mathrm{N} 1)}=1.012, \\
\mathrm{~d}_{(\mathrm{H} 2-\mathrm{N} 2)}=1.009\end{array}$ & $\begin{array}{c}3446.24 \mathrm{~cm}^{-1} \\
3502.9 \mathrm{~cm}^{-1}\end{array}$ \\
\hline SW & $\begin{array}{l}\text { B3, } \\
\text { N1 }\end{array}$ & +1.16 & 1.41 & $\begin{array}{r}\mathrm{d}_{(\mathrm{H}-\mathrm{H})}=1.687, \\
\mathrm{~d}_{(\mathrm{H} 1-\mathrm{N} 1)}=1.004, \\
\mathrm{~d}_{(\mathrm{H} 2-\mathrm{B} 3)}=1.190, \\
\mathrm{~d}_{(\mathrm{B} 3-\mathrm{N} 1)}=2.632\end{array}$ & $\begin{array}{l}2543.6 \mathrm{~cm}^{-1} \\
3572.7 \mathrm{~cm}^{-1}\end{array}$ \\
\hline $\mathrm{B}_{\mathrm{N}}$ & $\begin{array}{l}\text { B1, } \\
\text { B4 }\end{array}$ & -1.51 & -1.35 & $\begin{array}{l}\mathrm{d}_{(\mathrm{H}-\mathrm{H})}=1.757, \\
\mathrm{~d}_{(\mathrm{H} 1-\mathrm{B} 4)}=1.207, \\
\mathrm{~d}_{(\mathrm{H} 2-\mathrm{B} 4)}=1.274, \\
\mathrm{~d}_{(\mathrm{H} 2-\mathrm{B} 2)}=1.315, \\
\mathrm{~d}_{(\mathrm{B} 1-\mathrm{B} 4)}=1.858\end{array}$ & $\begin{array}{l}2051.7 \mathrm{~cm}^{-1} \\
2440.0 \mathrm{~cm}^{-1}\end{array}$ \\
\hline
\end{tabular}

On $d h$-BN with $\mathrm{V}_{\mathrm{N}}$, two hydrogen atoms $(2 \mathrm{H})$ prefer to bind to $B$ atoms near $\mathrm{N}$ vacancy such that they $(2 \mathrm{H})$ are on the opposite side of the $d h-\mathrm{BN}$ sheet and the difference in their $\mathrm{z}$ coordinates is $2.934 \AA$ (Figure 4a). The adsorption energy of $2 \mathrm{H}$ is found to be $-1.61 \mathrm{eV}$. On $d h-\mathrm{BN}$ with $\mathrm{V}_{\mathrm{B}}$, shown in Figure $4 \mathrm{~b}, 2 \mathrm{H}$ prefer to attach to $\mathrm{N}$ atoms near the $\mathrm{B}$ vacancy in such a way that the two $\mathrm{H}$ atoms are on the opposite side of the sheet with a difference in their z-position of $1.490 \AA$. The adsorption energy of $2 \mathrm{H}$ on $d h$-BN with $\mathrm{V}_{\mathrm{B}}$ is $-4.61 \mathrm{eV}$, an extremely exothermic adsorption. For the case of two hydrogens adsorption on $d h-\mathrm{BN}$ with SW, the $\mathrm{H}$ atoms prefer to stay on the same side of SW as shown in Figure 4c, in which one hydrogen attaches to B3 while the other attaches to $\mathrm{N} 1$. We find that the adsorption of $2 \mathrm{H}$ atoms on $\mathrm{SW}$ breaks the bond of B3-N1, with the distance $\mathrm{d}_{(\mathrm{B} 3-\mathrm{N} 1)}$ of $2.632 \AA$, largely increased from $1.487 \AA$ in the absence of the $\mathrm{H}$ atoms. This adsorption is endothermic with energy of $+1.16 \mathrm{eV}$, the 
positive sign signifying that it is not favored, mainly because there is no undercoordinated site at the SW. For the case of $2 \mathrm{H}$ adsorption on $d h$-BN with $\mathrm{B}_{\mathrm{N}}$, one hydrogen prefers to adsorb on the center boron atom (B4) whereas the other prefers to stay at the bridge between B1 and B4, as shown in Figure $4 \mathrm{~d}$. The adsorption energy of this configuration is $-1.51 \mathrm{eV}$.

Charge density difference (CDD) plots, shown in the bottom panels of Figure 4, indicate noticeable rearrangement of electron density and electron transfer. For $\mathrm{V}_{\mathrm{N}}$ and $\mathrm{B}_{\mathrm{N}}$, the $d h$ $\mathrm{BN}$ donates $1.168 \mathrm{e}$ and 1.098 e to the atomic hydrogens, respectively. For $V_{B}$, the defect gains 0.902 e from atomic hydrogens. In the case of SW, there is 0.120 e transferring from $d h$-BN to atomic hydrogens. We also find that the adsorption of $2 \mathrm{H}$ has effect on the electronic density of states of $d h$-BN (Figure 5). Overall, our calculations indicate that atomic hydrogen atoms adsorb most strongly on $d h-B N$ with a $V_{B}$ defect $\left(E_{a d s}=-4.73 \mathrm{eV}\right)$ and not at all when the defect is $S W\left(E_{a d s}=+1.04\right.$ $\mathrm{eV})$. The inclusion of zero-point energy correction changes the binding energy of $2 \mathrm{H}$ to $d h-\mathrm{BN}$ to $-1.32,-4.13,+1.41$, and -1.35 eV with $V_{N}, V_{B}, S W$, and $B_{N}$, respectively,

The adsorption of $\mathrm{H}$ on the defects create either $\mathrm{B}-\mathrm{H}, \mathrm{N}-\mathrm{H}$, or both on the $d h-\mathrm{BN}$ sheets. The vibrational frequencies of the stretching mode of the bonds should play an important role in determining the defect sites to which $\mathrm{H}$ adsorbs to. The notable vibrational frequencies of such modes are listed in Table 1 and their corresponding vibrational pattern are shown in Figure 6. $(\mathrm{a})_{40}$

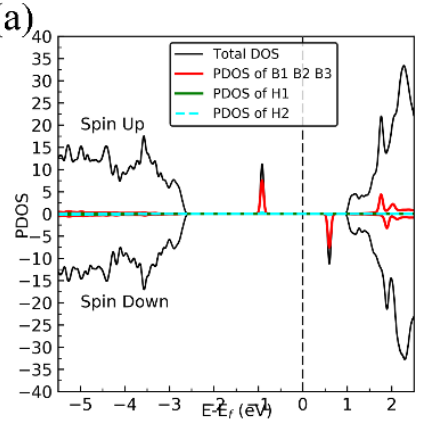

(c)

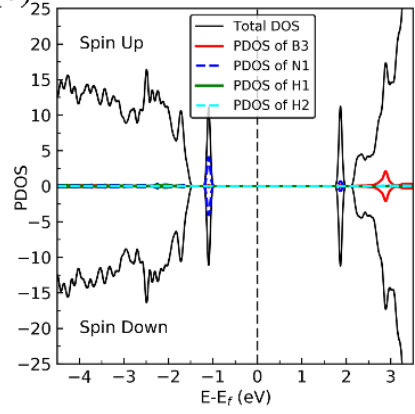

(b)

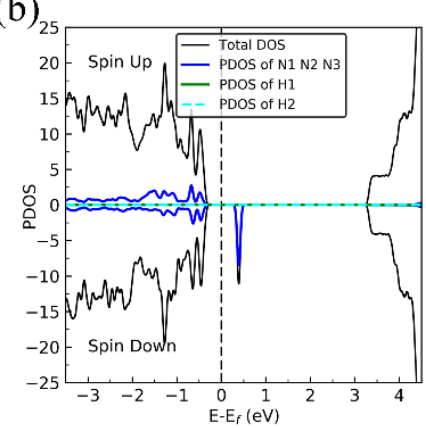

(d)

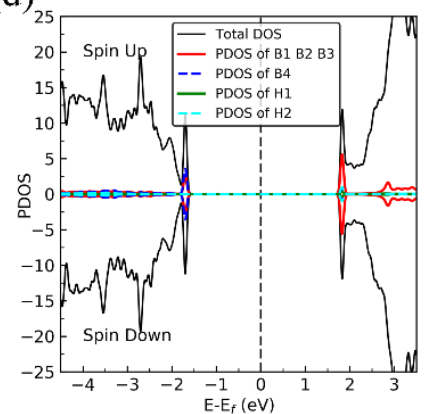

Figure 5 Spin-polarized total density of states (TDOS) (black line), spin-polarized PDOS of defect area in (red line or blue line) and spin-polarized PDOS adsorbed two hydrogens (green line and cyan line) of $2 \mathrm{H}-d h$-BN with (a) $\mathrm{V}_{\mathrm{N}},(\mathrm{b}) \mathrm{V}_{\mathrm{B}}$, (c) SW, and (d) $\mathrm{B}_{\mathrm{N}}$, respectively. The position of the Fermi level $\left(E_{F}\right)$ is indicated by dashed line.

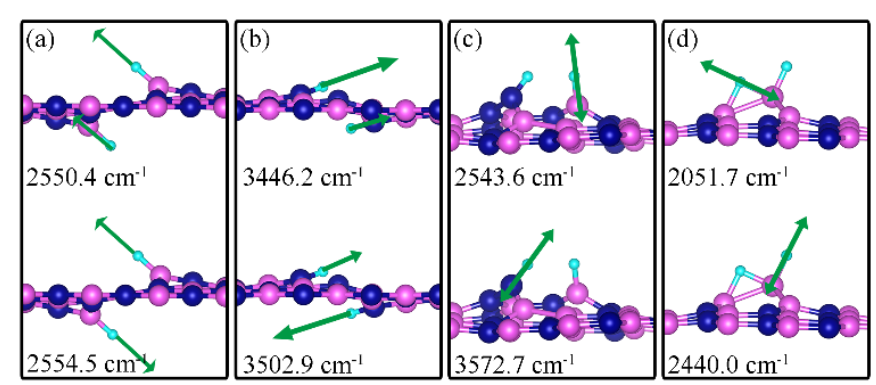

Figure 6 Notable vibration pattern of two hydrogen atoms adsorbed on $d h-\mathrm{BN}$ with a) $\left.\left.V_{N}, b\right) V_{B}, c\right) S W$, and d) $B_{N}$ defect. The magenta, blue, black and light blue balls represent the $\mathrm{B}, \mathrm{N}$, and $\mathrm{H}$ atoms, respectively. Arrows indicate displacement directions.

\section{CO on dh-BN}

Carbon monoxide ( $\mathrm{CO}$ ) is one of the major common toxic gases in the atmosphere and is the main component of syngas, the essential reactant for (higher) alcohol synthesis. Figure 7 shows the geometric structure of the lowest energy configuration of $\mathrm{CO}$ adsorption on the $\mathrm{V}_{\mathrm{N}}, \mathrm{V}_{\mathrm{B}}, \mathrm{SW}$, and $\mathrm{B}_{\mathrm{N}}$. Table 2 summarizes the binding energy, geometric parameters, and notable frequencies for the $\mathrm{CO}$ binding on the four types of defects in $h$ BN.

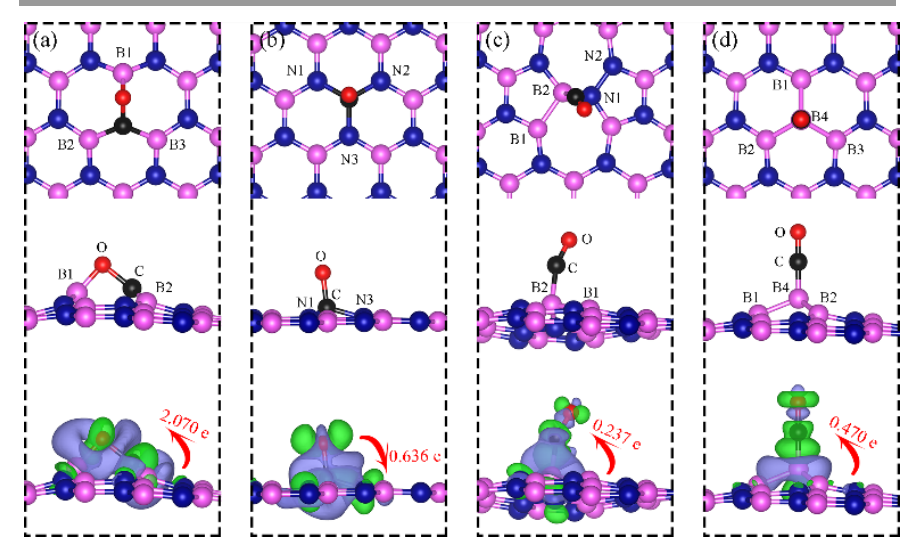

Figure 7 Top and side views of the most energetically favorable configurations of adsorbed $\mathrm{CO}$ on $d h$-BN with a) $V_{N}, b$ ) $\left.V_{B}, c\right) S W$, and d) $B_{N}$ type defect. The magenta, blue, black and red balls represent the $B, N, C$, and $O$ atoms, respectively. The top and middle panel shows the top and side views, respectively. Bottom: the corresponding side views of the geometric structures with the charge density difference. The green and violet isosurfaces with isovalue of $\pm 0.003 \mathrm{e} / \AA^{3}$, represent the accumulation and depletion of electron, respectively. The red arrow shows the electron transfer in direction and value using Bader charge analysis. 
(a)

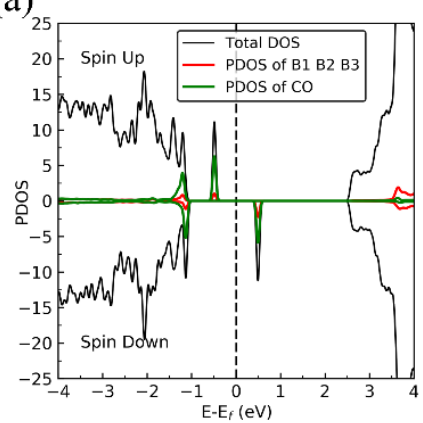

(c)

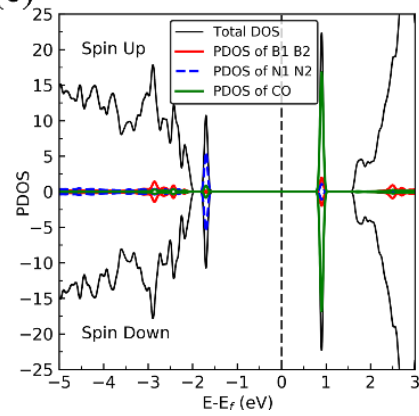

(b)

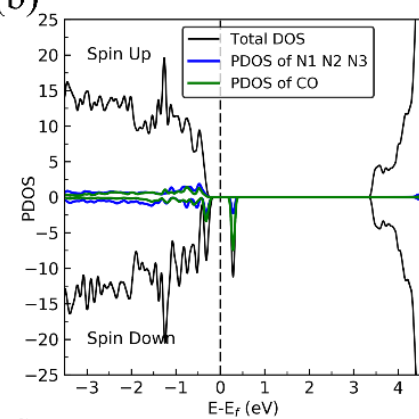

(d)

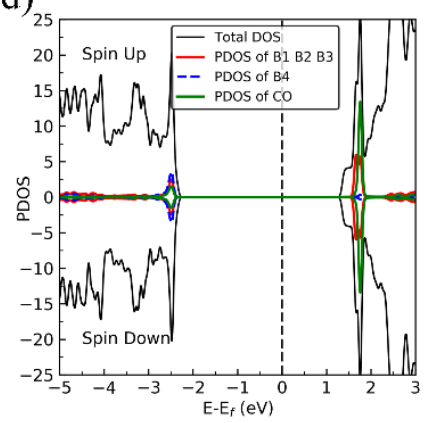

Figure 8 Spin-polarized total density of states (TDOS) (black line), spin-polarized PDOS of defect area in (red line or blue line) and spin-polarized PDOS adsorbed CO (green line) of CO-dh-BN with (a) $V_{N}$, (b) $V_{B}$, (c) SW, and (d) $B_{N}$, respectively. The position of the Fermi level $\left(E_{F}\right)$ is indicated by dashed line.

Table 2 The adsorption energy without $\left(E_{a d s}\right)$ and with $\left(E^{\prime}{ }_{\text {ads }}\right)$ ZPE correction, geometrical parameters, and notable frequencies for adsorption of $\mathrm{CO}$ on $\mathrm{dh}$-BN.

\begin{tabular}{|c|c|c|c|c|}
\hline Defects & $\begin{array}{l}\text { Eads } \\
(e V)\end{array}$ & $\begin{array}{l}E_{\text {ads }}^{\prime}( \\
\mathrm{eV}) \\
\mathrm{ZPE}\end{array}$ & $\begin{array}{c}\text { Bond length }(\AA) \text { and } \\
\text { Bond angle }\left({ }^{\circ}\right)\end{array}$ & $\begin{array}{c}\text { Notable } \\
\text { frequencies }\left(\mathrm{cm}^{-1}\right)\end{array}$ \\
\hline $\mathrm{V}_{\mathrm{N}}$ & -3.45 & -3.24 & $\begin{array}{l}\mathrm{d}_{(\mathrm{C}-\mathrm{O})}=1.403, \\
\mathrm{~d}_{(\mathrm{C}-\mathrm{B} 1)}=1.528, \\
\mathrm{~d}_{(\mathrm{O}-\mathrm{B} 1)}=1.417, \\
\theta_{(\mathrm{C}-\mathrm{O}-\mathrm{B} 1)}=93.5^{\circ}\end{array}$ & $\begin{array}{c}333.9,349.6 \\
1063.6\end{array}$ \\
\hline$V_{\text {B }}$ & -4.54 & -4.31 & $\begin{array}{c}\mathrm{d}_{(\mathrm{C}-\mathrm{O})}=1.386, \\
\mathrm{~d}_{(\mathrm{C}-\mathrm{N} 1)}=1.493, \\
\theta_{(\mathrm{O}-\mathrm{C}-\mathrm{N} 1)}=103.9^{\circ}\end{array}$ & $\begin{array}{c}117.3,141.6 \\
895.5,971.8,973.5\end{array}$ \\
\hline SW & 0.43 & 0.44 & $\begin{array}{c}\mathrm{d}_{(\mathrm{C}-\mathrm{O})}=1.150, \\
\mathrm{~d}_{(\mathrm{C}-\mathrm{B} 2)}=1.636, \\
\theta_{(\mathrm{O}-\mathrm{C}-\mathrm{B} 2)}=159.0^{\circ}\end{array}$ & $\begin{array}{c}54.2,243.1,397.9, \\
1986.9\end{array}$ \\
\hline $\mathrm{B}_{\mathrm{N}}$ & -2.53 & -2.45 & $\begin{array}{c}\mathrm{d}_{(\mathrm{C}-0)}=1.163, \\
\mathrm{~d}_{(\mathrm{C}-\mathrm{B} 4)}=1.444, \\
\theta_{(\mathrm{B} 4-\mathrm{C}-\mathrm{O})}=179.9^{\circ}\end{array}$ & $\begin{array}{c}43.4,46.7,266.6 \\
467.1,469.0 \\
1999.5 \\
\end{array}$ \\
\hline
\end{tabular}

\section{CO adsorption on $\mathbf{V}_{\mathrm{N}}$}

On $\mathrm{V}_{\mathrm{N}}, \mathrm{CO}$ binds at the defect sites with $\mathrm{O}$ atom bonded to $\mathrm{B} 1$ atom and $\mathrm{C}$ atom bonded to two $\mathrm{B} 2$ and $\mathrm{B} 3$, as shown in Figure $7 a$, agree with previously reported results. ${ }^{40,41}$ The adsorption causes out-of-plane displacement of the B1 atom by about $1 \AA$, which is quite large. The $\mathrm{CO}$ bond length increases from $1.134 \AA$ (gas phase) to $1.403 \AA$ (adsorbed), while $\mathrm{d}_{(\mathrm{C}-\mathrm{B} 2)}\left(\mathrm{d}_{(\mathrm{C}-\mathrm{B} 3)}\right)$ and $\mathrm{d}_{(\mathrm{O}-\mathrm{B})}$ are calculated to be 1.528 and $1.417 \AA$, respectively. The CO bond length of $1.403 \AA$ suggests that a bond order of 1 of the $C$ $O$ bond, i.e. adsorption causes scission of the two $\pi$-bonds of the $\mathrm{CO}$ molecule, making it ready for further reaction such as dissociation or hydrogenation. The adsorption energy of $\mathrm{CO}$ on $d h-\mathrm{BN}\left(\mathrm{V}_{\mathrm{N}}\right)$ is $-3.45 \mathrm{eV}$, which is not far from $-4.04 \mathrm{eV}$ or $-3.97 \mathrm{eV}$

reported elsewhere. ${ }^{40,41}$ The adsorption energy is $-3.24 \mathrm{eV}$ with ZPE correction. The Bader charge analysis shows that 2.070 e is transferred from the $d h-\mathrm{BN}$ to the $\mathrm{CO}$ molecule. As shown in the bottom panel of Figure 7a, a sizable electron density accumulation (green region) appeared between the $B$ atom and $C$ atom, and between the $B$ atom and $O$ atom, which verifies the bonding formation of the $\mathrm{B}-\mathrm{C}$ bond and $\mathrm{B}-\mathrm{O}$ bond. A loss of electron density (violet region) is shown around the $\mathrm{C}-\mathrm{O}$ bond, confirming that adsorption weakens the $\mathrm{C}-\mathrm{O}$ bond by breaking its two $\pi$-bonds. In Figure 8a, which contains PDOS of $\mathrm{CO}$ adsorption on dh-BN $\left(\mathrm{V}_{\mathrm{N}}\right)$, the orbital mixing between the occupied states of $\mathrm{CO}$ molecules (in red line) and the states of B atoms (around the vacancy in blue line). This obvious overlap of states of $\mathrm{CO}$ and $\mathrm{V}_{\mathrm{N}}$ indicates the strong chemisorption of the $\mathrm{CO}$ molecule caused by dangling bonds of the $\mathrm{B}$ atoms around the vacancy site. In addition, the peaks in the density of states shift toward the higher energy since a charge transfer takes place from the $d h-\mathrm{BN}$ surface to the CO molecule.

The strong adsorption of $\mathrm{CO}$ on $\mathrm{V}_{\mathrm{N}}$ with both $\mathrm{C}$ and $\mathrm{O}$ bond to Boron atoms of $d h$-BN significantly affect the CO stretching mode. We found that its frequency is $1063.6 \mathrm{~cm}^{-1}$, as compared to that of $2115.0 \mathrm{~cm}^{-1}$ of the isolated CO molecule. This is a large shift and reflects the strong bond of $\mathrm{CO}$ with the support. In addition, we found that there are several vibrational modes that show strong coupling between $\mathrm{CO}$ and $d h$-BN whose frequencies are listed in Table 2 and whose vibrational pattern are shown in Figure 9.

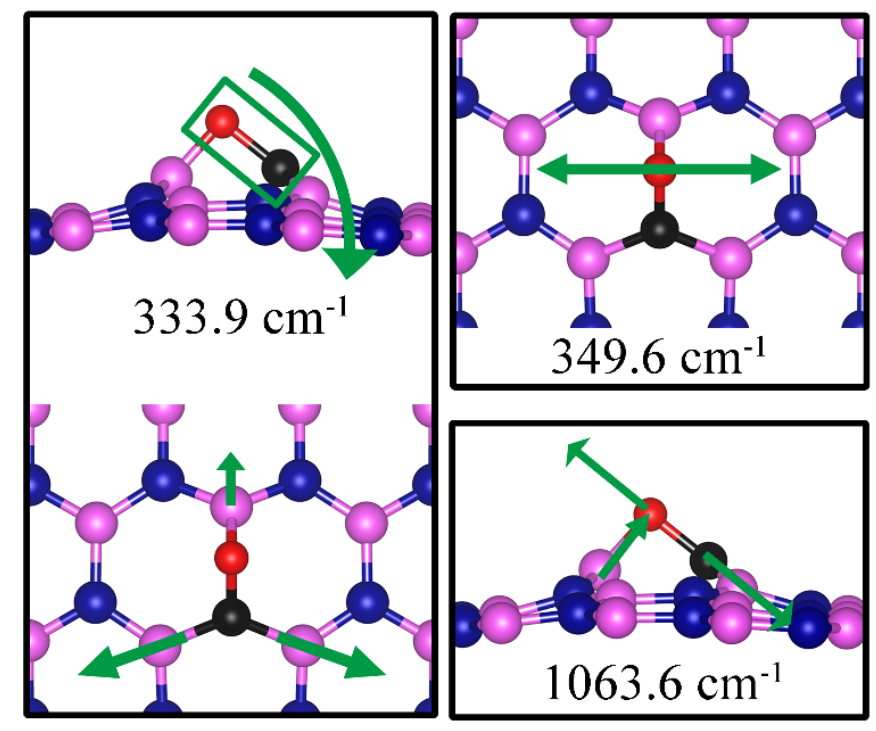

Figure 9 Notable vibrational modes of $\mathrm{CO}$ adsorbed on $d h-\mathrm{BN}$ with $\mathrm{V}_{\mathrm{N}}$. The magenta, blue, black and red balls represent the $\mathrm{B}, \mathrm{N}, \mathrm{C}$, and $\mathrm{O}$ atoms, respectively. Arrows indicate vibrational patterns.

\section{CO adsorption on $V_{B}$}

The most stable adsorption configuration of $\mathrm{CO}$ adsorption on $V_{B}$ is shown in Figure $7 \mathrm{~b}$. In this configuration, $C O$ binds to $N 1$, $\mathrm{N} 2$ and N3 atoms in a vertical orientation via $\mathrm{C}-\mathrm{N}$ bond, which is similar to that previously reported. ${ }^{40,41} \mathrm{C}-\mathrm{O}$ bond length increases from $1.143 \AA$, in gas phase $\mathrm{CO}$, to $1.386 \AA$, while $\mathrm{d}_{(\mathrm{C}-\mathrm{N})}$ is found to be $1.501 \AA$. The $\mathrm{CO}$ bond length is larger than that of 
a typical bond order 2, but smaller than that of a typical bond order 1 . The adsorption energy is $-4.54 \mathrm{eV}(-4.31 \mathrm{eV}$ with ZPE correction), which is smaller than that of -5.63 or $-5.86 \mathrm{eV}$ reported elsewhere. ${ }^{40,41}$ The difference arises from the form of the exchange-correlation functional used in DFT calculations. The Bader charge analysis shows that about $0.636 \mathrm{e}$ is transferred from the $\mathrm{CO}$ molecule to the support. In the bottom panel of Figure $7 b$, a sizable electron density accumulation (green region) appeared between the $\mathrm{C}$ and $\mathrm{N}$ atoms, which affirms the strong interaction between the $\mathrm{CO}$ molecule and $\mathrm{N}$ atoms around the vacancy. A loss of electron density (violet region) surrounds the region between $C$ and $O$ atoms, which shows a weakened $\mathrm{C}-\mathrm{O}$ bond. In Figure $8 \mathrm{~b}$, PDOS of $\mathrm{CO}$ adsorption on $d h-\mathrm{BN}$ at $\mathrm{V}_{\mathrm{B}}$ around the Fermi level shows orbital mixing between the occupied states of the $\mathrm{CO}$ molecules and orbitals of $\mathrm{B}$ atoms, indicating chemisorption of $\mathrm{CO}$ on $d h-\mathrm{BN}$. Similar to $\mathrm{CO}$ adsorption on $\mathrm{V}_{\mathrm{N}}$, the strong adsorption of $\mathrm{CO}$ on the $V_{B}$ defect significantly affects the $C O$ stretching mode. We found that its frequency is $895.5 \mathrm{~cm}^{-1}$, as compared to 2115.0 $\mathrm{cm}^{-1}$ of the isolated $\mathrm{CO}$ molecule. Such large change is consistent with the elongation of $\mathrm{CO}$ bond length upon adsorption. In addition, we found that there are several vibrational modes that show strong coupling between $\mathrm{CO}$ and $d h$-BN, whose frequencies are listed in Table 2 and whose displacement patterns are illustrated in Figure 10.

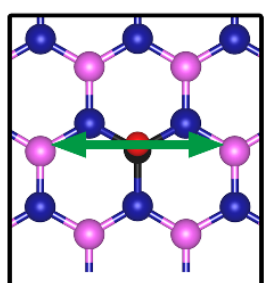

$117.3 \mathrm{~cm}^{-1}$

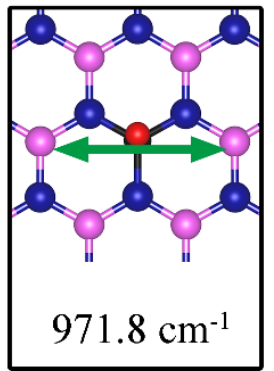

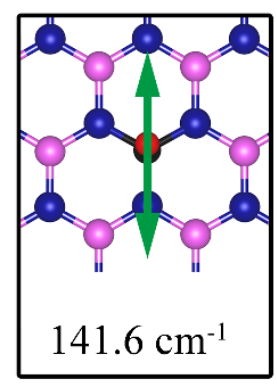

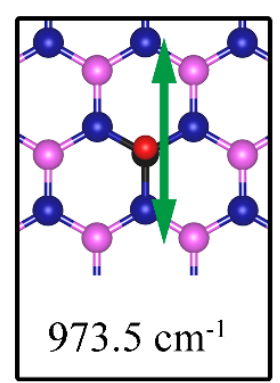

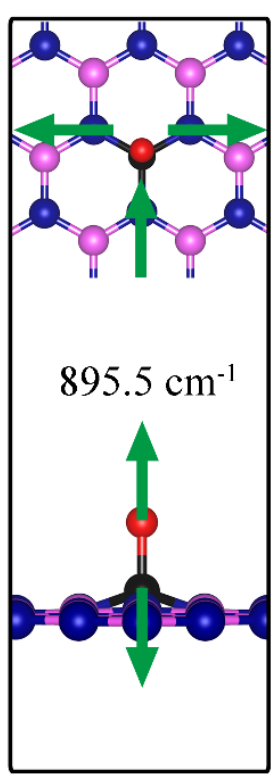

Figure 10 Notable vibrational modes of $\mathrm{CO}$ adsorption on $d h-\mathrm{BN}$ with $\mathrm{V}_{\mathrm{B}}$. The magenta, blue, black and red balls represent the $B, N, C$, and $\mathrm{O}$ atoms, respectively. Arrows indicate vibrational patterns.

\section{CO adsorption on SW}

The most energetically favorable configuration of $\mathrm{CO}$ adsorption on $\mathrm{SW}$ is shown in Figure 7c. $\mathrm{CO}$ adsorbs at the $\mathrm{B}$ site by pulling the $\mathrm{B}$ atom out from the $d h-\mathrm{BN}$ plane. In this geometry, the bond length of $\mathrm{C}-\mathrm{O}$ is $1.150 \AA$ and the bond length of $C-B$ is $1.636 \AA$. The adsorption energy of $C O$ is found to be $0.43 \mathrm{eV}$ ( $0.44 \mathrm{eV}$ with ZPE correction), which is significantly different from that of $-0.58 \mathrm{eV}$ reported in a previous study ${ }^{42}$.
While both studies show a similar adsorption configuration, the difference in binding energies may again be attributed to the exchange correlation functional used in the DFT calculations. For further validating our results, we calculate adsorption energy of CO on SW when it is physisorbed. We found that the physisorption energy is $-0.12 \mathrm{eV}$, indicating that the $\mathrm{CO}$ molecule prefers to be in the physisorbed state. We also performed Nudged Elastic Band ${ }^{43,44}$ calculation between the physisorbed and chemisorbed configurations and found that there is an barrier of $0.57 \mathrm{eV}$ for the physisobed molecule to adsorb chemically on the SW defect. Bader charge analysis of the chemisorbed $\mathrm{CO}$ on SW shows 0.237 e transferred from the surface to $\mathrm{CO}$. The charge density difference plot of $\mathrm{CO}$ on $\mathrm{dh}$ BN (SW) as shown in the bottom panel of Figure 7c indicates a sizable electron density accumulation (green region) between the $\mathrm{B}$ and $\mathrm{C}$ atoms, consistent with the formation of $\mathrm{B}-\mathrm{C}$ bond. However $\mathrm{B}-\mathrm{C}$ bond length is $1.636 \AA$, longer than that in the cases of $C O$ on $V_{N}$ and $V_{B}$ defects, indicating that the strength of $\mathrm{CO}$ binding on $d h-\mathrm{BN}$ with SW is weaker than that on $d h-\mathrm{BN}$ with $V_{N}$, consistent with calculated positive adsorption energies. PDOS in Figure $8 \mathrm{c}$ shows that the conduction band moves toward lower energy and that the valence band shifts toward higher energy, reducing the band gap of $d h$-BN, albeit the energy gap is still large and there is no available electronic state that is at or close to the Fermi level.
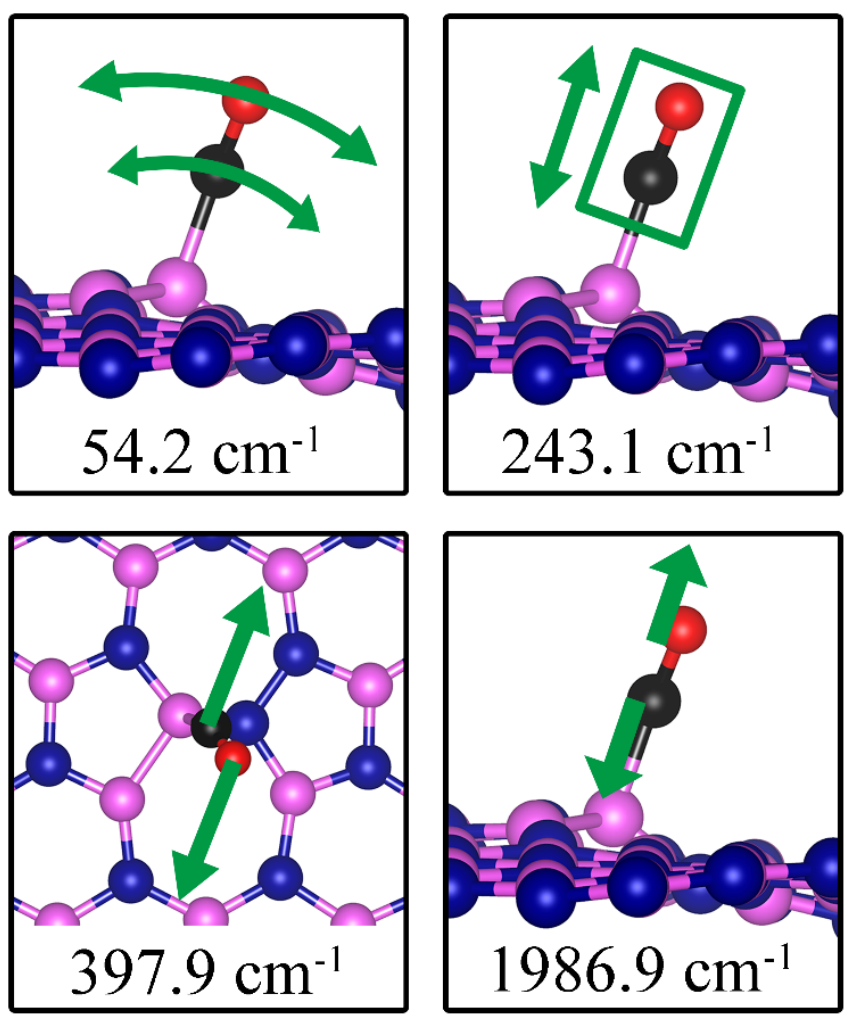

Figure 11 Notable vibrational modes of $\mathrm{CO}$ adsorption on $d h$-BN with SW defect. The magenta, blue, black and red balls represent the $B, N, C$, and $O$ atoms, respectively. Arrows indicate vibrational patterns. The rectangular encloses the atoms that concertedly move. 
As the strength of the adsorption of $\mathrm{CO}$ on SW is much reduced as compared to that on $\mathrm{V}_{\mathrm{B}}$ and $\mathrm{V}_{\mathrm{N}}$, the CO stretching frequency is found to be $1987 \mathrm{~cm}^{-1}$. This mode is softer than that in isolated $\mathrm{CO}$ molecule due to the reduction in strength of $\mathrm{CO}$ bond and its elongation upon adsorption. In addition, we found that there are several vibrational modes that show strong contribution from $\mathrm{C}$ and $\mathrm{O}$ movements whose frequencies are listed in Table 2 and whose displacement patterns are shown in Figure 11.

\section{CO adsorption on $B_{N}$}

Figure $7 \mathrm{~d}$ shows the energetically favored configuration of the adsorption of $\mathrm{CO}$ on $d h-\mathrm{BN}$ with $\mathrm{B}_{\mathrm{N}}$, in which $\mathrm{CO}$ binds perpendicularly on top of the central $B$ atom (labeled as B4) with an adsorption energy of $-2.53 \mathrm{eV}(-2.45 \mathrm{eV}$ with ZPE correction). The calculated bond length $\mathrm{d}_{(\mathrm{C}-\mathrm{B})}$ and $\mathrm{d}_{(\mathrm{C}-\mathrm{O})}$ are is $1.444 \AA$ and $1.163 \AA$ (elongated by $\sim 0.03 \AA$ from that in gasphase), respectively. CDD plot of $\mathrm{CO}$ on $d h-\mathrm{BN}$ with $\mathrm{B}_{\mathrm{N}}$ shown in the bottom panel of Figure $7 d$ indicates a sizable electron density accumulation (green region) between the $B$ and $C$ atoms, confirming the strong interaction between the $\mathrm{CO}$ molecule and its neighboring $B$ atoms around the defect area. A small loss of electron density (violet region) is seen over the C$\mathrm{O}$ bond, indicating weakening of the $\mathrm{C}-\mathrm{O}$ bond, consistent with its elongation (from $1.134 \AA$ in gas phase to $1.163 \AA$ ). A large loss of electron density (violet region) is found over the B4-B1, B4-B2 and B4-B3 bonds, suggesting that the bonds are weakened on $\mathrm{CO}$ adsorption. Bader charge analysis shows a net 0.470 e transferred from $d h-\mathrm{BN}$ (with $\mathrm{B}_{\mathrm{N}}$ ) to CO. After CO adsorption on $d h-\mathrm{BN}$ with $\mathrm{B}_{\mathrm{N}}$, the density of states peaks shift toward lower energy, as shown in Figure 8d. More importantly, the defect states merge with the valence and conduction bands, suggesting the absence of dangling bonds and the inability of more molecules to adsorb, thus passivating the catalytic activity of $d h-\mathrm{BN}$ with $\mathrm{B}_{\mathrm{N}}$.

The stretching frequency of the adsorbed CO molecule on $d h$ $\mathrm{BN}$ with $\mathrm{B}_{\mathrm{N}}$ is found to be $1999 \mathrm{~cm}^{-1}$. This mode is slightly softer than that in isolated $\mathrm{CO}$ molecule commensurate with small reduction in strength of the $\mathrm{CO}$ bond as a result of slight elongation upon adsorption. In addition, we found that there are several vibrational modes that show strong coupling between $\mathrm{CO}$ and $d h-\mathrm{BN}$, vibrational patterns of six of which are shown in as shown in Figure 12.
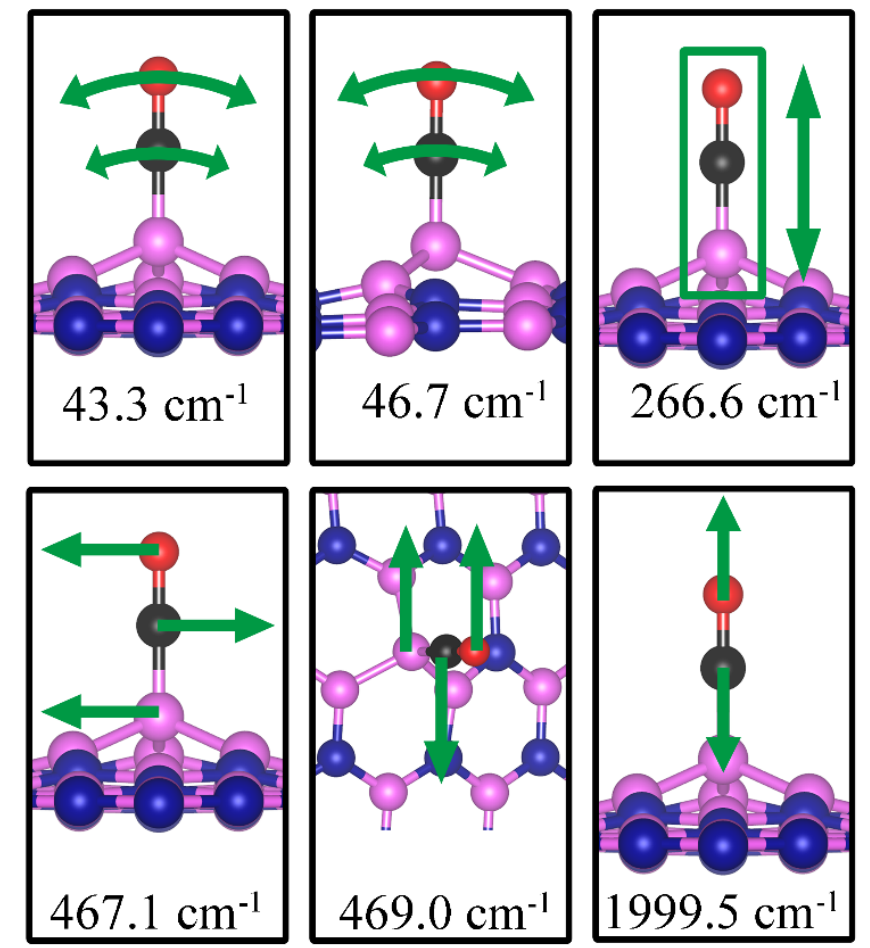

Figure 12 Notable vibrational modes of $\mathrm{CO}$ adsorption on $d h-\mathrm{BN}$ with $\mathrm{B}_{\mathrm{N}}$. The magenta, blue, black and red balls represent the $B, N, C$, and $O$ atoms, respectively. Arrows indicate vibrational patterns. The rectangular encloses the atoms that are concertedly move together.

\section{$\mathrm{CO}_{2}$ on $d h-\mathrm{BN}$}

The geometry structure of $\mathrm{CO}_{2}$ adsorption on the $\mathrm{V}_{\mathrm{N}}, \mathrm{V}_{\mathrm{B}}, \mathrm{SW}$, and $\mathrm{B}_{\mathrm{N}}$ are shown in Figure 13. The corresponding adsorption energies and geometric parameters are summarized in Table 3.

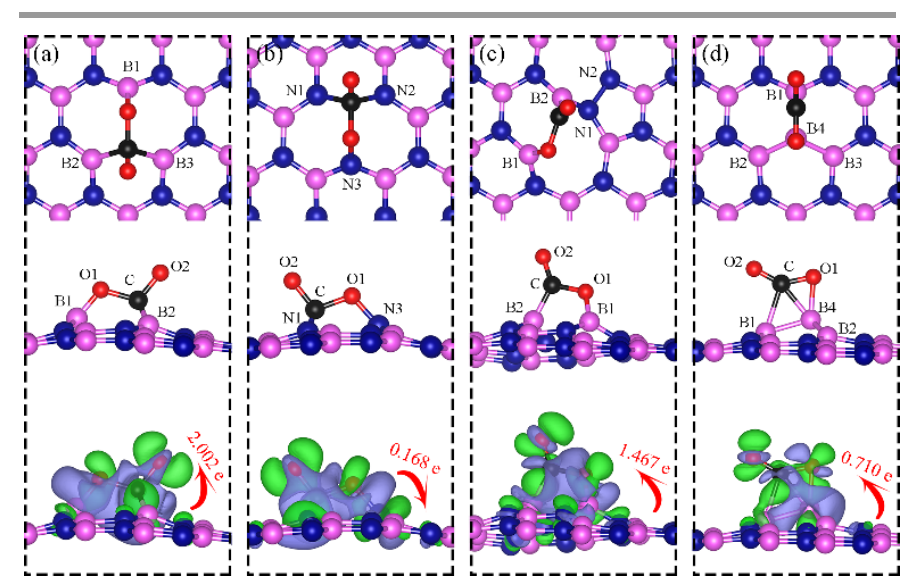

Figure 13 Top and side views of the most energetically favorable configurations of adsorbed $\mathrm{CO}_{2}$ on the $d h$ - $\mathrm{BN}$ with a) $\mathrm{V}_{\mathrm{N}}$, b) $\mathrm{V}_{\mathrm{B}}, \mathrm{c}$ ) SW, and d) $\mathrm{B}_{\mathrm{N}}$. The magenta, blue, black and red balls represent the $\mathrm{B}, \mathrm{N}, \mathrm{C}$, and $\mathrm{O}$ atoms, respectively. The top and middle panel shows the top and side views, respectively. Bottom: the corresponding side views of the geometric structures with the charge density difference plot. The green and violet isosurfaces with isovalue of $\pm 0.003 \mathrm{e} / \AA^{3}$, represent the accumulation and depletion of electron, respectively. The red arrow shows the electron transfer in direction and value. 
Table 3 The adsorption energy without $\left(E_{\text {ads }}\right)$ and with $\left(E^{\prime}{ }^{\prime}\right.$ as $)$ ZPE correction and geometrical parameters for adsorption of $\mathrm{CO}_{2}$ on $d h-\mathrm{BN}$.

\begin{tabular}{|c|c|c|c|c|}
\hline Defects & $\begin{array}{l}E_{\text {ads }} \\
(\mathrm{eV})\end{array}$ & $\begin{array}{l}E_{\text {ads }}^{\prime} \\
(\mathrm{eV})\end{array}$ & $\begin{array}{c}\text { Bond length }(\AA \AA) \text { and } \\
\text { Bond angle }\left({ }^{\circ}\right)\end{array}$ & $\begin{array}{c}\text { Notable } \\
\text { frequencies }(\mathrm{cm}-1)\end{array}$ \\
\hline $\mathrm{V}_{\mathrm{N}}$ & -1.83 & -1.73 & $\begin{array}{l}\mathrm{d}_{(\mathrm{C}-01)}=1.438 \\
\mathrm{~d}_{(\mathrm{C}-02)}=1.311 \\
\mathrm{~d}_{(\mathrm{C}-\mathrm{B} 2)}=1.672 \\
\mathrm{~d}_{(\mathrm{O} 1-\mathrm{B} 1)}=1.382 \\
\theta_{(\mathrm{O} 1-\mathrm{C}-02)}=113.7^{\circ}\end{array}$ & $\begin{array}{c}95.7,250.7,253.4 \\
373.2,667.6 \\
1193.2,1296.6\end{array}$ \\
\hline$V_{B}$ & -0.62 & -0.48 & $\begin{array}{l}\mathrm{d}_{(\mathrm{C}-01)}=1.409 \\
\mathrm{~d}_{(\mathrm{C}-\mathrm{O} 2)}=1.353 \\
\mathrm{~d}_{(\mathrm{C}-\mathrm{N} 1)}=1.496 \\
\mathrm{~d}_{(\mathrm{O} 1-\mathrm{N} 3)}=1.446 \\
\theta_{(\mathrm{O} 1-\mathrm{C}-\mathrm{O} 2)}=107.1^{\circ}\end{array}$ & $\begin{array}{c}141.8,1006.0 \\
1073.1\end{array}$ \\
\hline SW & 0.49 & 0.51 & $\begin{array}{l}\mathrm{d}_{(\mathrm{C}-\mathrm{O} 1)}=1.405 \\
\mathrm{~d}_{(\mathrm{C}-\mathrm{O} 2)}=1.209 \\
\mathrm{~d}_{(\mathrm{C}-\mathrm{B} 2)}=1.582, \\
\mathrm{~d}_{(\mathrm{O} 1-\mathrm{B} 1)}=1.412 \\
\theta_{(\mathrm{O} 1-\mathrm{C}-\mathrm{O} 2)}=121.9^{\circ}\end{array}$ & $\begin{array}{c}124.6,157.8 \\
753.1,839.5 \\
1225.0,1715.6\end{array}$ \\
\hline $\mathrm{B}_{\mathrm{N}}$ & -0.10 & -0.10 & $\begin{aligned} \mathrm{d}_{(\mathrm{C}-01)}=1.273 \\
\mathrm{~d}_{(\mathrm{C}-02)}=1.206 \\
\mathrm{~d}_{(\mathrm{C}-81)}=1.989 \\
\mathrm{~d}_{(\mathrm{C}-\mathrm{B})}=1.807 \\
\mathrm{~d}_{(01-\mathrm{B}) \mathrm{B})}=1.661 \\
\theta_{(01-\mathrm{C}-02)}=139.6^{\circ}\end{aligned}$ & $\begin{array}{c}103.6,612.2 \\
1081.5,1802.2\end{array}$ \\
\hline
\end{tabular}

(a)

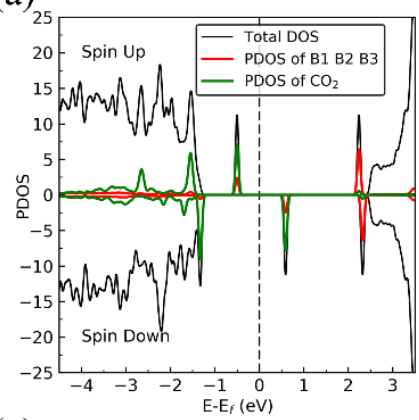

(b)

(c)

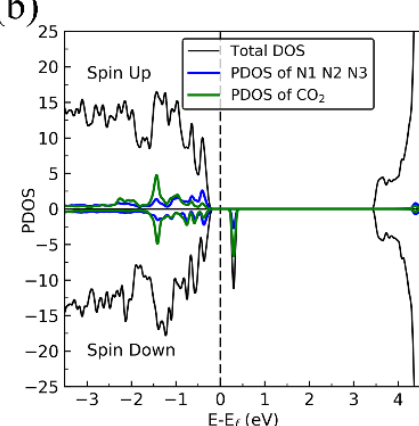

(d)
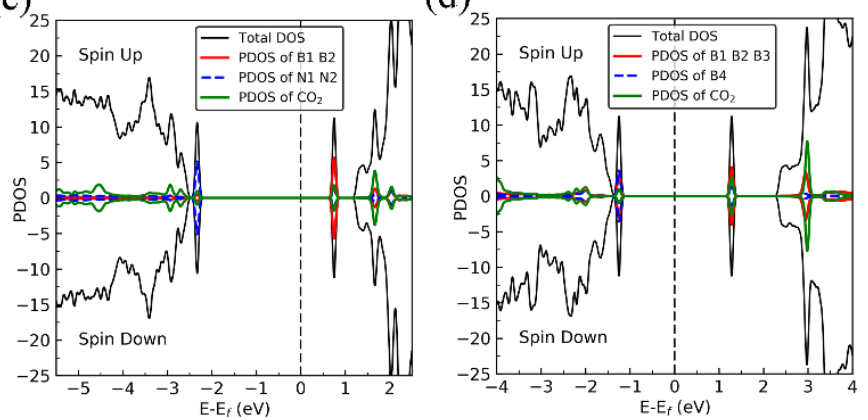

Figure 14 Spin-polarized total density of states (TDOS) (black line), spin-polarized PDOS of defect area in (red line or blue line) and spin-polarized PDOS adsorbed $\mathrm{CO}_{2}$ (green line) of $\mathrm{CO}_{2}-d h$-BN with (a) $\mathrm{V}_{N}$, (b) $\mathrm{V}_{\mathrm{B}}$, (c) SW, and (d) $\mathrm{B}_{\mathrm{N}}$, respectively. The position of the Fermi level (EF) is indicated by dashed line.

\section{$\mathrm{CO}_{2}$ adsorption on $\mathrm{V}_{\mathrm{N}}$}

On dh-BN with $\mathrm{V}_{\mathrm{N}}, \mathrm{CO}_{2}$ binds at the defect sites, with an adsorption energy of $-1.83 \mathrm{eV}(-1.73 \mathrm{eV}$ with ZPE correction), indicating a strong chemisorption of the $\mathrm{CO}_{2}$ molecule at the vacancy site. As shown in Figure 13a, the adsorption pulls B1, $\mathrm{B} 2$ and $\mathrm{B} 3$ atoms slightly out of the $d h$-BN plane and the $\mathrm{CO}_{2}$ molecule lies in the proximity of three boron sites near the vacancy with bond lengths, $d_{(O 1-B 1)}$, and $d_{(C-B 2)}\left(d_{(C-B 3)}\right)$, of 1.382 and $1.672 \AA$, respectively. The molecule is bent with the $\mathrm{O} 1-\mathrm{C}-$ $\mathrm{O} 2$ angle of 107.1 o. The bond lengths, $\mathrm{d}_{(\mathrm{C}-\mathrm{O} 1)}$ and $\mathrm{d}_{(\mathrm{C}-\mathrm{O} 2)}$, are 1.438 and $1.311 \AA$, respectively (both are longer than that of $1.172 \AA$ of gas phase $\mathrm{CO}_{2}$ ), indicating that the original $\mathrm{C}-\mathrm{O}$ bonds are stretched upon interaction between $\mathrm{CO}_{2}$ and $d h-\mathrm{BN}$ with $\mathrm{V}_{\mathrm{N}}$. Bader charge analysis shows that about 2.002 e transferred from $d h$-BN to the $\mathrm{CO}_{2}$ molecule. $\mathrm{CDD}$ plot of $\mathrm{CO}_{2}$ on $d h$-BN with $\mathrm{V}_{\mathrm{N}}$, shown in the bottom panel of Figure 13a, indicates a sizable electron density accumulation (green region) appearing between the B2 (B3) and C atoms and between the B1 and $O$ atoms, consistent with the formation of new bonds B2(B3)-C and $\mathrm{B} 1-\mathrm{C}$. A loss of electron density (violet region) between $\mathrm{C}-$ $\mathrm{O}$ is also consistent with the elongation and weakening of the $\mathrm{C}-\mathrm{O}$ bond. PDOS shown in Figure 14a indicates overlaps, i.e. hybridizations, between states of $\mathrm{CO}_{2}$ molecule and the states of $\mathrm{B}$ atoms, indicating the chemisorption of $\mathrm{CO}_{2}$ on the $d h-\mathrm{BN}$ with $\mathrm{V}_{\mathrm{N}}$ and the strong interaction between the molecule and the $d h$-BN sheet. We also find that the defect states, i.e. the ones near the Fermi level, are mostly contributed from $\mathrm{CO}_{2}$ and shifted toward lower energy, closer to VBM. This phenomenon indicates that the defect states have migrated (transferred) to the adsorbed $\mathrm{CO}_{2}$ molecules.

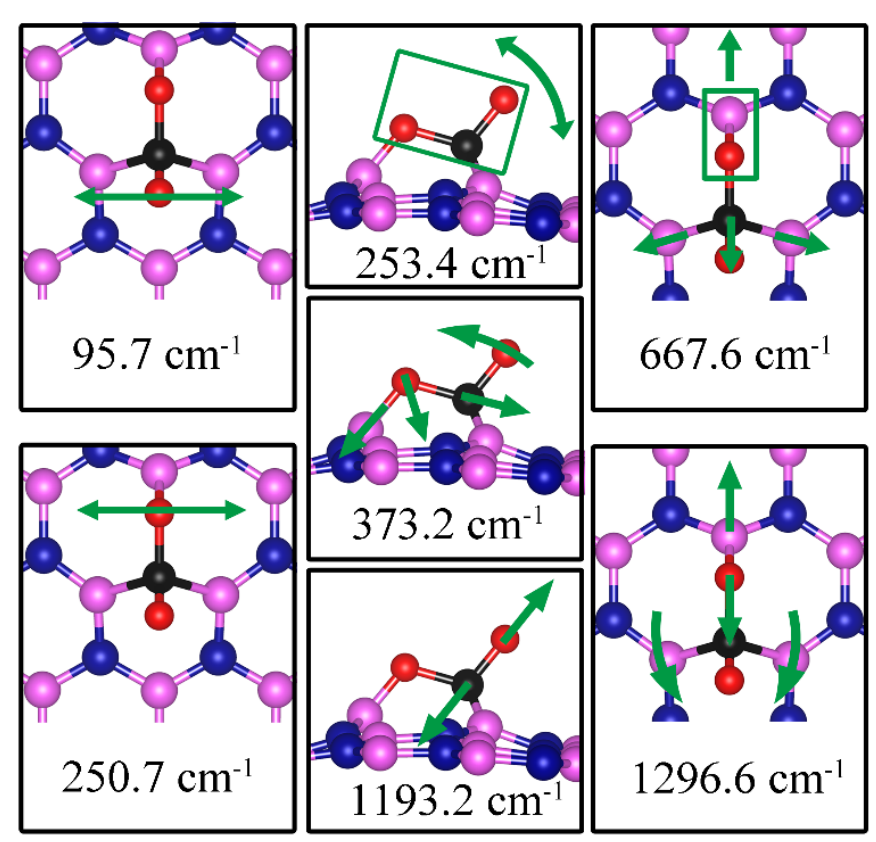

Figure 15 Notable vibrational modes of $\mathrm{CO}_{2}$ adsorption on $d h-\mathrm{BN}$ with $\mathrm{V}_{\mathrm{N}}$. The magenta, blue, black and red balls represent the $\mathrm{B}, \mathrm{N}, \mathrm{C}$, and $\mathrm{O}$ atoms, respectively. Arrows indicate vibrational patterns. The rectangular encloses the atoms that move together.

Since $\mathrm{CO}_{2}$ adsorbs on $d h$-BN with a bent configuration, the normal vibrational mode of $\mathrm{CO}_{2}$ molecule (symmetric stretching, antisymmetric stretching, bending) are absent. Instead, we found few notable vibrational modes that include contributions from the adsorbed $\mathrm{CO}_{2}$ molecules, as shown in 
Figure 15, with their frequencies listed in Table 3. Among them, the stretching mode of the $\mathrm{C}-\mathrm{O}$ bond is of particular interest as it is infra-red active and its frequency is $1193.2 \mathrm{~cm}^{-1}$, which is different from that $\left(1063.6 \mathrm{~cm}^{-1}\right)$ of the adsorbed CO molecule on the same defect.

\section{$\mathrm{CO}_{2}$ adsorption on $\mathrm{V}_{\mathrm{B}}$}

On $d h$-BN with $\mathrm{V}_{\mathrm{B}}, \mathrm{CO}_{2}$ binds at the $\mathrm{N}$ sites with an adsorption energy of $-0.62 \mathrm{eV}$ (-0.48 eV with ZPE correction). Figure $13 \mathrm{~b}$ shows the corresponding adsorption configuration, in agreement with that reported in previous work, ${ }^{45}$ which also reported a binding energy of $-0.62 \mathrm{eV}$. In this configuration, $\mathrm{CO}_{2}$ lies in between the three $\mathrm{N}$ sites with bond lengths, $\mathrm{d}_{(\mathrm{C}-\mathrm{N} 1)}$ and $\mathrm{d}_{(\mathrm{O}-\mathrm{N} 3)}$, of $1.496 \AA$ and $1.446 \AA$, respectively. The bond lengths, $\mathrm{d}_{(\mathrm{C}-\mathrm{O} 1)}$ and $\mathrm{d}_{(\mathrm{C}-\mathrm{O} 2)}$, are $1.409 \AA$ and $1.353 \AA$ (longer than that $1.172 \AA$ of an isolated molecule), respectively, indicating weakening of the $\mathrm{C}-\mathrm{O}$ bonds. The Bader charge analysis shows 0.168 e transferred from the molecule to the $d h-\mathrm{BN}$. CDD plot of $\mathrm{CO}_{2}$ on $d h-\mathrm{BN}$ with $\mathrm{V}_{\mathrm{B}}$ shown in Figure $13 \mathrm{~b}$ shows a sizable electron density accumulation (green region) between the $\mathrm{N}$ and $\mathrm{C}$ atoms, confirming the formation of $\mathrm{N}-\mathrm{C}$ bond, and a loss of electron density (violet region) between the $\mathrm{C}$ and $\mathrm{O}$ atoms, consistent with the weakening of $\mathrm{C}-\mathrm{O}$ bonds. PDOS shown in Figure 14b indicates hybridizations of electronic states of the adsorbed $\mathrm{CO}_{2}$ molecule and defects states of $d h-\mathrm{BN}$ with $\mathrm{V}_{\mathrm{B}}$, confirming the chemisorption of the molecule. It also suggests that the dangling bonds at the $\mathrm{N}$ atoms at defect site of $d h$-BN are partially saturated, as the contributions of $\mathrm{N}$ atoms to the defect states are reduced as compared to that in the absence of $\mathrm{CO}_{2}$.
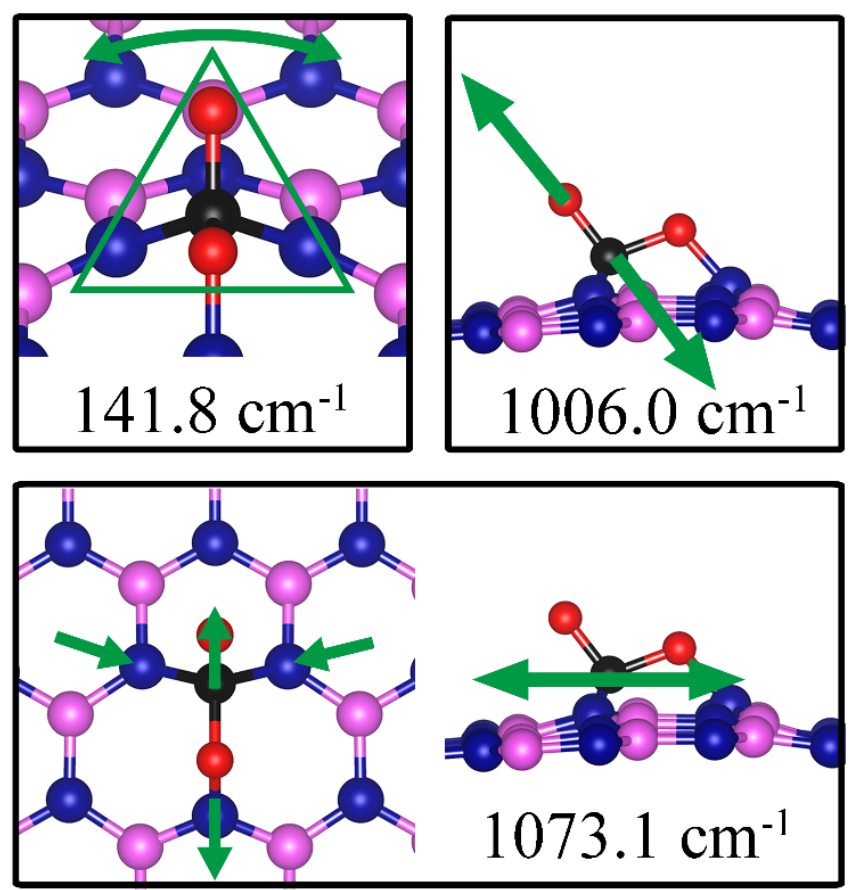

Figure 16 Notable vibrational modes of $\mathrm{CO}_{2}$ adsorption on $d h$ - $\mathrm{BN}$ with $\mathrm{V}_{\mathrm{B}}$. The magenta, blue, black and red balls represent the $B, N, C$, and $O$ atoms, respectively. Arrows indicate vibrational patterns. The trapezium-like shape in $141.8 \mathrm{~cm}^{-1}$ mode encloses the group of atoms that concertedly vibrate together.
Similar to the case of $\mathrm{CO}_{2}$ adsorbed on the $d h-\mathrm{BN}$ with $\mathrm{V}_{\mathrm{N}}$, the molecule is found to adsorb with a bent configuration on $V_{B}$, thus the normal vibrational mode of $\mathrm{CO}_{2}$ molecule (symmetric stretching, antisymmetric stretching, bending) are not present. We found again three notable vibrational modes that show contributions from the adsorbed $\mathrm{CO}_{2}$ molecules, as shown in Figure 16, with their frequencies listed in Table 3. The stretching mode of the $\mathrm{C}-\mathrm{O}$ bond that points outward from $d h-\mathrm{BN}$ has a frequency of $1006.0 \mathrm{~cm}^{-1}$. This mode is also infrared-active and we assign this mode as a signature for the identification of the adsorption of $\mathrm{CO}_{2}$ on the $d h-\mathrm{BN}$ with $\mathrm{V}_{\mathrm{N}}$.

\section{$\mathrm{CO}_{2}$ adsorption on SW}

On $d h$-BN with $\mathrm{SW}, \mathrm{CO}_{2}$ binds at two $\mathrm{B}$ sites with adsorption energy of $+0.36 \mathrm{eV}(0.44 \mathrm{eV}$ with ZPE correction) indicating that the adsorption is endothermic. As shown in Figure 13c, the adsorbed $\mathrm{CO}_{2}$ pulls the $\mathrm{B}$ atom out of the $d h-\mathrm{BN}$ plane. The two $\mathrm{C}-\mathrm{O}$ bond lengths are found to be with $1.405 \AA$ (C-O1) and $1.209 \AA$ ( $C-O 2)$. The bond lengths, $\mathrm{d}_{(\mathrm{C}-\mathrm{B} 2)}$ and $\mathrm{d}_{(\mathrm{O} 1-\mathrm{B} 1)}$, are $1.582 \AA$ and $1.412 \AA$, respectively. Bader charge analysis shows $1.456 \mathrm{e}$ transferred from $d h-B N$ with SW to the molecule. CDD plot of $\mathrm{CO}_{2}$ on $d h-\mathrm{BN}$ with SW, as shown in Figure $13 \mathrm{c}$, indicates a sizable electron density accumulation (green region) appeared between the $B$ and $C$ atoms and between the $B$ and $O$ atoms and, suggesting covalent bond formation between the pairs of atoms and a large loss of electron density in the region between the $\mathrm{B} 1$ and $\mathrm{B} 2$ atoms, indicating weakening of the B-B bond of the defect. PDOS, as shown in Figure 14c, indicates that the conduction band moves toward lower energy while the valence band shifts toward higher energy, similar to case of CO on dhBN with SW. It also shows that contributions from B1, B2, N1, and $\mathrm{N} 2$ atoms to the defect states are still dominant while only small contribution of the adsorbed $\mathrm{CO}_{2}$ is observed, implying a weak interaction between $\mathrm{CO}_{2}$ and $d h-\mathrm{BN}$ with $\mathrm{SW}$. This weak interaction and the energy-costs for bending the $\mathrm{CO}_{2}$ molecule and for breaking $\mathrm{B}-\mathrm{B}$ bond at the $\mathrm{SW}$ are the reasons why the adsorption of $\mathrm{CO}_{2}$ on $d h-\mathrm{BN}$ with $\mathrm{SW}$ is endothermic.

Even though the adsorption is endothermic, we have calculated the vibrational frequencies for the above configurations. We found four notable vibrational modes that are localize at or near the adsorbed $\mathrm{CO}_{2}$. Their vibrational patterns are shown in Figure 17 and their frequencies are listed in Table 3. In this configuration, we found that the stretching mode of the $\mathrm{C}-\mathrm{O}$ bond that points outward from the defect has a frequency of $1715.6 \mathrm{~cm}^{-1}$. This mode is infrared active and could be the signature of this adsorption configuration. 


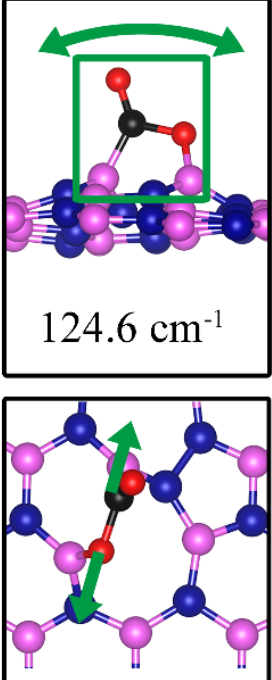

$839.5 \mathrm{~cm}^{-1}$
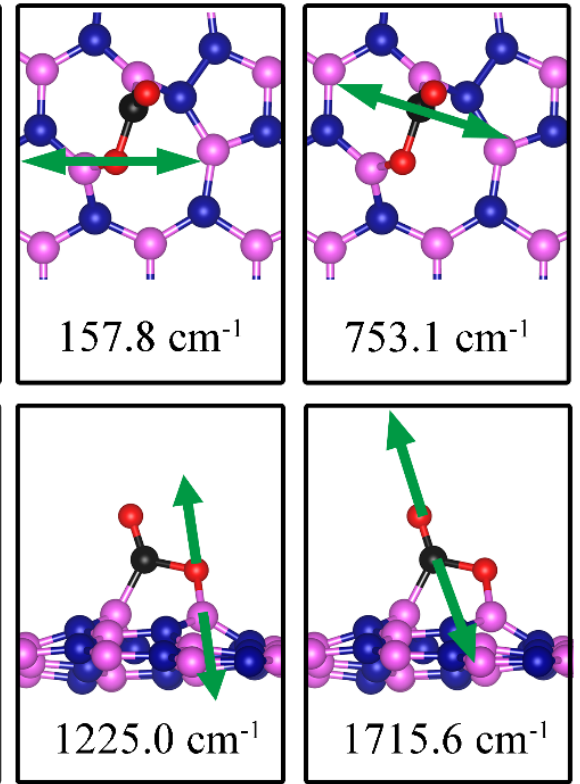

Figure 17 Notable vibrational modes of $\mathrm{CO}_{2}$ adsorption on $d h$-BN with SW. The magenta, blue, black and red balls represent the $\mathrm{B}, \mathrm{N}, \mathrm{C}$, and $\mathrm{O}$ atoms, respectively. Arrows indicate vibrational patterns. The square in $124.6 \mathrm{~cm}^{-1}$ mode figure (left) encloses all atoms that concertedly vibrate together.

\section{$\mathrm{CO}_{2}$ adsorption on $\mathrm{B}_{\mathrm{N}}$}

On dh-BN with $\mathrm{B}_{\mathrm{N}}$ as shown in Figure $13 \mathrm{~d}$, the adsorbed $\mathrm{CO}_{2}$ molecule undergoes structural distortion to a bent geometry with bond order reduction of $\mathrm{C}-\mathrm{O}$ bonds in a way similar to that reported for $\mathrm{CO}_{2}$ chemisorption on B-rich BNNTs. ${ }^{39}$ The O1-C$\mathrm{O} 2$ bond angle is 139.6을 and the $\mathrm{C}-\mathrm{O} 1$ and $\mathrm{C}-\mathrm{O} 2$ bonds are significantly elongated to 1.206 and $1.273 \AA$, respectively, indicating bond-order reductions. The $\mathrm{B} 4$ atom at the defect site is pulled out of $d h$-BN plane considerably by $\sim 1 \AA$. The adsorption energy of $\mathrm{CO}_{2}$ adsorbed at the $\mathrm{B}_{N}$ is found to be -0.10 $\mathrm{eV}$ (ZPE correction does not change the value), which is significantly lower than that of $-0.74 \mathrm{eV}$ reported for B-rich BNNTs. ${ }^{39}$ The Bader charge analysis shows $0.710 \mathrm{e}$ is transferred from the $d h-\mathrm{BN}$ to the molecule. $\mathrm{CDD}$ plot of $\mathrm{CO}_{2}$ on $d h-\mathrm{BN}$ with $B_{N}$, as shown in Figure $13 d$, indicates a sizable electron density accumulation (green region) in the region between the $B$ and $C$ atoms and between the $B$ and $O$ atoms and a large loss of electron density (violet region) in the region between the $B 1$ atom and $\mathrm{B} 2$ atom, indicating the weakening of $\mathrm{B}-\mathrm{B}$ bond. The $\mathrm{CO}_{2}$ adsorption on $d h-\mathrm{BN}$ with $\mathrm{B}_{\mathrm{N}}$ thus cause the density of states to shift toward higher energy (Figure 14d), consistent with direction of electron transfer from $d h-\mathrm{BN} N$ to the $\mathrm{CO}_{2}$ molecule.

We found two notable vibrational modes that display large contribution from the adsorbed $\mathrm{CO}_{2}$ molecule. The displacement patterns of these modes are shown in Figure 18 and their frequencies are listed in Table 3. The stretching mode of the $\mathrm{C}-\mathrm{O}$ bond that points outward from the $d h-\mathrm{BN}$ plane has a frequency of $1802.2 \mathrm{~cm}^{-1}$. This mode is infrared active and we assign it as the signature of the adsorption configuration discussed above.
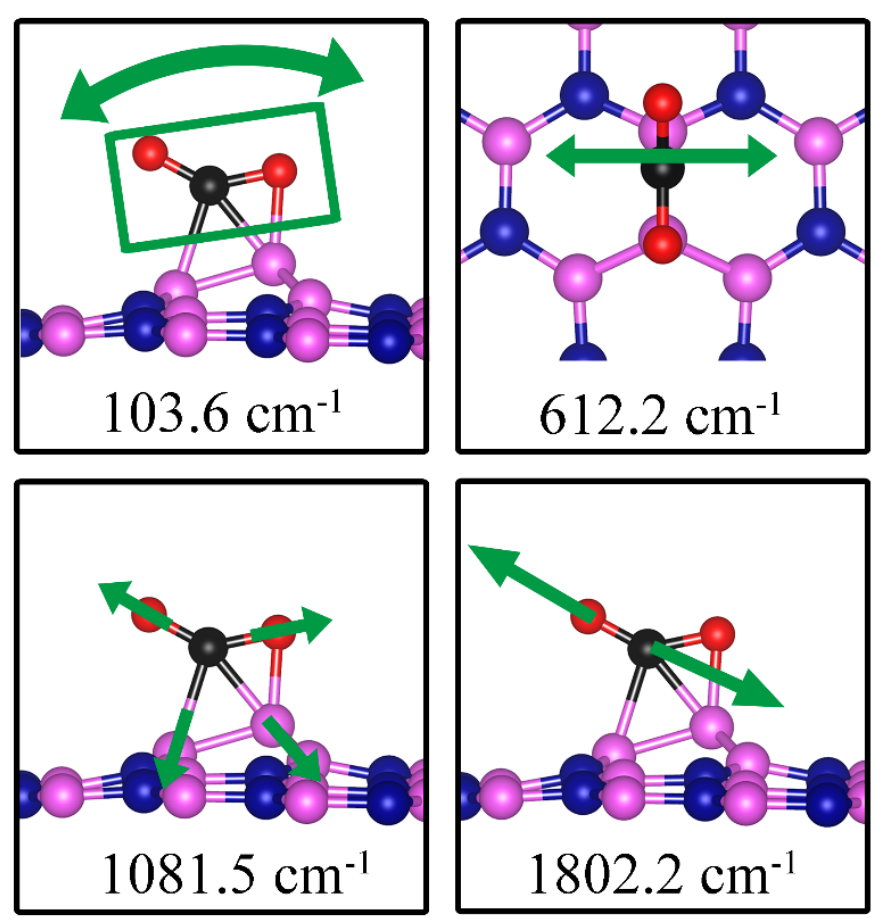

Figure 18 Notable vibrational modes of $\mathrm{CO}_{2}$ adsorption on $d h-\mathrm{BN}$ with $\mathrm{B}_{\mathrm{N}}$. The magenta, blue, black and red balls represent the $B, N, C$, and $O$ atoms, respectively. Arrows indicate vibrational patterns. The rectangular in the left figure encloses atoms that concertedly vibrate together.

\section{Catalytic Properties of dh-BN}

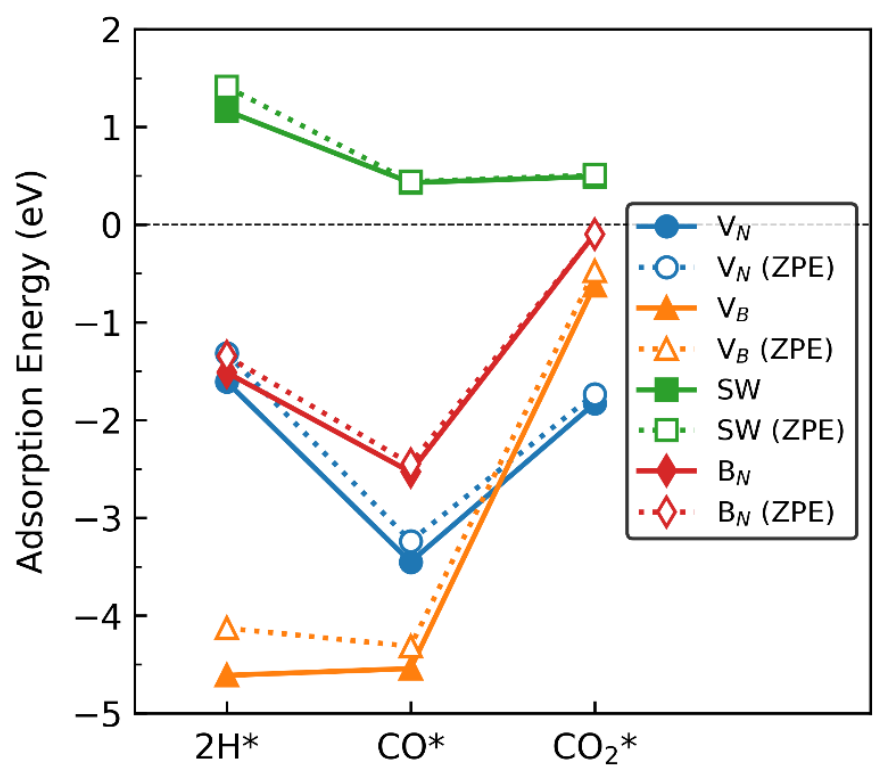

Figure 19 Adsorption energy of $2 \mathrm{H}, \mathrm{CO}$, and $\mathrm{CO}_{2}$ on the $d h$-BN with (a) $\mathrm{V}_{\mathrm{N}},(\mathrm{b}) \mathrm{V}_{\mathrm{B}}$, (c) SW, and (d) $B_{N}$, shown with circle, triangle, square, and diamond markers, respectively. Values without and with ZPE corrections are shown in solid and empty markers, respectively. The markers for each defect types are connected with solid or dotted lines for guiding the eyes. 
This section discusses the implication of our finding for catalytic application of $d h-\mathrm{BN}$ for hydrogenations of $\mathrm{CO}$ and $\mathrm{CO}_{2}$. To facilitate these reactions, it is important that co-adsorption of $\mathrm{CO}$ or $\mathrm{CO}_{2}$ with $\mathrm{H}_{2}$ be feasible on the defects. Our results presented above suggest that $\mathrm{H}$ atoms can be chemisorbed on the defects while molecular adsorption leads to physisorption. Figure 19 shows comparison of the adsorption energy of $2 \mathrm{H}$, $\mathrm{CO}$, and $\mathrm{CO}_{2}$. On $d h-\mathrm{BN}$ with $\mathrm{SW}$, adsorptions of $2 \mathrm{H}, \mathrm{CO}$ and $\mathrm{CO}_{2}$ on SW are endothermic (positive adsorption energies), suggesting that these adsorptions are not favored, and thus hydrogenation of $\mathrm{CO}$ or $\mathrm{CO}_{2}$ are not feasible on such type of defect. On $d h$-BN with $\mathrm{V}_{\mathrm{B}}$, on the other hand, adsorption energies of $2 \mathrm{H}$ and $\mathrm{CO}$ are similar and in the range from -4 to $5 \mathrm{eV}$, suggesting rather strong adsorption. Such strong adsorption, however, often lead to difficulties in the removal or diffusion of the adsorbates (reactants) and for co-adsorption to occur. It is most likely that the $V_{B}$ sites will remain occupied by $\mathrm{H}$ or $\mathrm{CO}$ during a reaction, thus deactivating the site. Moreover, with the $\mathrm{V}_{\mathrm{B}}$ defect adsorption of $\mathrm{CO}_{2}$ is substantially weaker than that of $2 \mathrm{H}$, making it less likely should the site is occupied by $2 \mathrm{H}$. We thus conclude that $d h-\mathrm{BN}$ with $\mathrm{V}_{\mathrm{B}}$ is also not suitable for $\mathrm{CO}_{2}$ hydrogenation. Similarly, on $d h-\mathrm{BN}$ with $\mathrm{B}_{\mathrm{N}}$, adsorption of $\mathrm{CO}_{2}$ is a weak chemisorption, implying that $\mathrm{CO}_{2}$ could easily desorb before it would have the opportunity to react with other species under reaction condition. On the other hand, the strength of $2 \mathrm{H}$ and $\mathrm{CO}$ adsorptions are similar and strong for stable adsorptions. However, the PDOS of adsorption of $2 \mathrm{H}$ and $\mathrm{CO}$ on $d h-\mathrm{BN}$ with $\mathrm{B}_{\mathrm{N}}$, as shown in Figure 5 and Figure 8 , respectively, do not show any mid-gap state, indicating there is no dangling bond in the band gap for more molecules to adsorb. The above lead us to surmise that for such a defect coadsorption is less likely to occur. The situation is different for $d h$ - $\mathrm{BN}$ with $\mathrm{V}_{\mathrm{N}}$. With this particular defect we find that while the binding of $\mathrm{CO}$ is strong (adsorption energy of $-3.24 \mathrm{eV}$ with ZPE correction) - suggesting that CO could occupy and deactivate the site - the adsorption energies of $2 \mathrm{H}$ and $\mathrm{CO}_{2}$ are in a similar range that is not too strong to block active sites or not too weak to be stable. The above comparisons lead us to suggest that $d h$-BN with $\mathrm{V}_{\mathrm{N}}$ could be a potential catalyst for $\mathrm{CO}_{2}$ hydrogenation. This is in agreement with similar conclusion obtained for the hydrogenation of olefins. ${ }^{6}$

\section{Conclusions}

Our systematic analysis of the electronic structure and vibrational dynamics of syngas molecules adsorbed on defectladen single-layer $h$-BN, using density functional theory based calculations, has allowed us to make a distinction among four types defects $\left(V_{N}, V_{B}, S W\right.$, and $\left.B_{N}\right)$ that we considered. We find that $\mathrm{CO}$ and $\mathrm{CO}_{2}$ molecules chemisorb on $d h$-BN for each of the four defect types, while $\mathrm{H}_{2}$ only physisorbs on these defects. On the other hand, atomic hydrogen adsorbs on the defects. The above conclusions are also supported by analysis of the partial density of electronic states and charge density difference plots. In addition, our calculations of vibrational frequencies for the considered adsorptions point to a number of notable vibrational modes that could help in the identification of defect type, through their experimental examination such as infrared absorption spectroscopy of the adsorbed molecules on $d h$-BN. Our results provide fundamental insights into the interaction of syngas molecules and $d h$-BN through which we can prescreen the defect type that would make the basal plane of the $d h-\mathrm{BN}$ catalytically active for $\mathrm{CO}$ and $\mathrm{CO}_{2}$ hydrogenation reactions. In particular, by comparing the adsorption energy of the molecules on $d h-\mathrm{BN}$ with each of the four defect types, accompanied with analysis on their electronic and geometric structures, we suggest that $d h-\mathrm{BN}$ with $\mathrm{V}_{\mathrm{N}}$ (nitrogen vacancy) as a good candidate catalyst for $\mathrm{CO}_{2}$ hydrogenation. We await experimental results that validate our findings.

On a more general note, although we have focused mostly on the chemical activity of defect-laden $h$-BN in this work, as we mention in the introduction, this interesting low-dimensional material is also being proposed as a single photon emitter in which defects play a major and their characterization is a challenge. Our work provides signatures in the vibrational modes of the adsorbed molecules that are strikingly different for the four defect types and thus could serve to identify them in experiments such as infra-red absorption spectroscopy which is commonly available. We hope our work encourages colleagues to undertake such measurement as probe of the nature of the defect in $h$-BN that gives rise to several novel properties.

\section{Conflicts of interest}

There are no conflicts to declare.

\section{Acknowledgments}

It is a pleasure to submit this work to a volume dedicated to Peter Toennies with whom TSR has had many fruitful scientific interactions over the years. She also remembers very fondly discussions with JPT at Schloss Ringberg and a particular challenging hike in the area which ended well. We also thank Richard Blair and Hannah Stern for many helpful discussions. This work was supported in part by the U.S. Department of Energy, under Grant DE-FG02-07ER15842. The DFT calculations were performed in part using the computing resources at STOKES in the Advanced Research Computing Center at University of Central Florida, at the National Energy Research Scientific Computing Center (NERSC). 


\section{Notes and references}

1. Y. Lin and J. W. Connell, Nanoscale, 2012, 4, 6908-6939.

2. K. Watanabe, T. Taniguchi and H. Kanda, Nat Mater, 2004, 3, 404-409.

3. R. Decker, Y. Wang, V. W. Brar, W. Regan, H.-Z. Tsai, Q. Wu, W. Gannett, A. Zettl and M. F. Crommie, Nano Lett., 2011, 11, 2291-2295.

4. Y. Li, Y. Rao, K. F. Mak, Y. You, S. Wang, C. R. Dean and T. F. Heinz, Nano Lett, 2013, 13, 3329-3333.

5. J. Di, J. Xia, M. Ji, B. Wang, S. Yin, Q. Zhang, Z. Chen and H. Li, Applied Catalysis B: Environmental, 2016, 183, 254-262.

6. D. J. Nash, D. T. Restrepo, N. S. Parra, K. E. Giesler, R. A. Penabade, M. Aminpour, D. Le, Z. Li, O. K. Farha, J. K. Harper, T. S. Rahman and R. G. Blair, ACS Omega, 2016, 1, 1343-1354.

7. J. T. Grant, C. A. Carrero, F. Goeltl, J. Venegas, P. Mueller, S. P. Burt, S. E. Specht, W. P. McDermott, A. Chieregato and I. Hermans, Science, 2016, 354, 1570-1573.

8. T. T. Tran, K. Bray, M. J. Ford, M. Toth and I. Aharonovich, Nat. Nanotechnol., 2016, 11, 37-41.

9. J. Feng, H. Deschout, S. Caneva, S. Hofmann, I. Lončarić, P. Lazić and A. Radenovic, Nano Lett., 2018, 18, 1739-1744.

10. R. Bourrellier, S. Meuret, A. Tararan, O. Stéphan, M. Kociak, L. H. G. Tizei and A. Zobelli, Nano Lett., 2016, 16, 4317-4321.

11. M. Topsakal, E. Aktürk and S. Ciraci, Phys. Rev. B, 2009, 79, 115442.

12. D. Le, T. B. Rawal and T. S. Rahman, J. Phys. Chem. C, 2014, 118, 5346-5351.

13. T. B. Rawal, D. Le and T. S. Rahman, J. Phys.: Condens. Matter 2017, 29, 415201

14. T. B. Rawal, D. Le and T. S. Rahman, J. Phys. Chem. C, 2017, 121, 7282-7293

15. P. E. Evans, H. K. Jeong, Z. Hooshmand, D. Le, T. B. Rawal, S. N. Alvillar, L. Bartels, T. S. Rahman and D. P. A., J. Phys. Chem C, 2018, 122 10042-10049.

16. C. S. Merida, D. Le, E. M. Echeverria, A. E. Nguyen, T. B. Rawal, S. Naghibi Alvillar, V. Kandyba, A. Al-Mahboob, Y. Losovyj, K. Katsiev, M. D. Valentin, C.-Y. Huang, M. J. Gomez, I. H. Lu, A. Guan, A. Barinov, T. S. Rahman, P. A. Dowben and L. Bartels, J. Phys. Chem. C, 2018, 122, 267-273.

17. H. Li, C. Tsai, A. L. Koh, L. Cai, A. W. Contryman, A. H. Fragapane, J. Zhao, H. S. Han, H. C. Manoharan, F. AbildPedersen, J. K. Norskov and X. Zheng, Nat Mater, 2016, 15, 4853.

18. B. Huang and H. Lee, Phys. Rev. B, 2012, 86, 245406

19. C. Jin, F. Lin, K. Suenaga and S. lijima, Phys. Rev. Lett., 2009, 102, 195505.

20. R. Schimmenti, R. Cortese, D. Duca and M. Mavrikakis, Chemcatchem, 2017, 9, 1610-1620.

21. S. Lin, X. Ye, R. S. Johnson and H. Guo, J. Phys. Chem. C, 2013, 117, 17319-17326.

22. X. Liu, T. Duan, C. Meng and Y. Han, RSC Adv., 2015, 5, 10452 10459.

23. Q. Sun, Z. Li, D. J. Searles, Y. Chen, G. M. Lu and A. Du, J. Am. Chem. Soc., 2013, 135, 8246-8253.

24. A. L. Gibb, N. Alem, J. H. Chen, K. J. Erickson, J. Ciston, A. Gautam, M. Linck and A. Zettl, J. Am. Chem. Soc., 2013, 135, 6758-6761.

25. C. K. Oliveira, E. F. A. Gomes, M. C. Prado, T. V. Alencar, R. Nascimento, L. M. Malard, R. J. C. Batista, A. B. de Oliveira, H. Chacham, A. M. de Paula and B. R. A. Neves, Nano Res., 2015, 8, 1680-1688.
26. I. N. Remediakis, F. Abild-Pedersen and J. K. Norskov, J. Phys. Chem. B, 2004, 108, 14535-14540.

27. Y. Choi and P. Liu, J. Am. Chem. Soc., 2009, 131, 13054-13061.

28. Y. Yang, J. Evans, J. A. Rodriguez, M. G. White and P. Liu, Phys. Chem. Chem. Phys., 2010, 12, 9909-9917.

29. H. Wu, X. Fan and J.-L. Kuo, Int. J. Hydrogen Energy, 2012, 37, 14336-14342.

30. W. Wang, S. Wang, X. Ma and J. Gong, Chem. Soc. Rev., 2011, 40, 3703-3727.

31. P. Giannozzi, S. Baroni, N. Bonini, M. Calandra, R. Car, C. Cavazzoni, D. Ceresoli, G. L. Chiarotti, M. Cococcioni, I. Dabo, A. Dal Corso, S. de Gironcoli, S. Fabris, G. Fratesi, R. Gebauer, U. Gerstmann, C. Gougoussis, A. Kokalj, M. Lazzeri, L. MartinSamos, N. Marzari, F. Mauri, R. Mazzarello, S. Paolini, A. Pasquarello, L. Paulatto, C. Sbraccia, S. Scandolo, G. Sclauzero, A. P. Seitsonen, A. Smogunov, P. Umari and R. M. Wentzcovitch, Journal of physics. Condensed matter : an Institute of Physics journal, 2009, 21, 395502.

32. P. E. Blöchl, Physical Review B, 1994, 50, 17953-17979.

33. G. Kresse and D. Joubert, Phys. Rev. B, 1999, 59, 1758-1775.

34. K. Lee, E. D. Murray, L. Z. Kong, B. I. Lundqvist and D. C. Langreth, Phys. Rev. B, 2010, 82, 081101.

35. W. Tang, E. Sanville and G. Henkelman, J. Phys.: Condens. Matter, 2009, 21, 084204

36. R. F. Bader, Acc. Chem. Res., 1985, 18, 9-15.

37. A. Togo and I. Tanaka, Scripta Mater., 2015, 108, 1-5.

38. R. Wang, J. Yang, X. Wu and S. Wang, Nanoscale, 2016, 8, 8210-8219.

39. H. Choi, Y. C. Park, Y. H. Kim and Y. S. Lee, J. Am. Chem. Soc., 2011, 133, 2084-2087.

40. Z. L. Liu, Q. Z. Xue, T. Zhang, Y. H. Tao, C. C. Ling and M. X. Shan, J. Phys. Chem. C, 2013, 117, 9332-9339.

41. K. Mao, L. Li, W. Zhang, Y. Pei, X. C. Zeng, X. Wu and J. Yang, Sci Rep, 2014, 4, 5441.

42. Y.-H. Zhang, K.-G. Zhou, X.-C. Gou, K.-F. Xie, H.-L. Zhang and Y. Peng, Chem. Phys. Lett., 2010, 484, 266-270.

43. G. Henkelman and H. Jonsson, J. Chem. Phys., 2000, 113, 99789985.

44. G. Henkelman, B. P. Uberuaga and H. Jonsson, J. Chem. Phys. 2000, 113, 9901-9904

45. Y. Jiao, A. Du, Z. Zhu, V. Rudolph, G. Q. Lu and S. C. Smith, Catal. Today, 2011, 175, 271-275. 